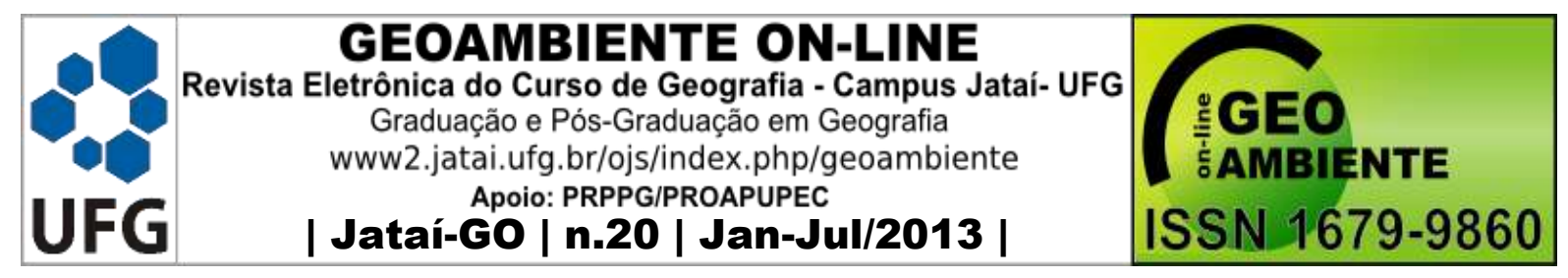

\title{
APLICAÇÃO DE GEOTECNOLOGIAS NO MONITORAMENTO DE PROJETOS DE RECOMPOSIÇÃO DE RESERVA LEGAL
}

\author{
Lucas Librelotto Abdala ${ }^{1}$; Fabricio Bau Dalmas ${ }^{2}$; Joanice Lube Battilani ${ }^{3}$; Antonio \\ Conceição Paranhos Filho'
}

(1 - Universidade Federal do Mato Grosso do Sul, Laboratório de Geoprocessamento para Aplicações Ambientais, lucas_abdala@hotmail.com; toniparanhos@gmail.com; 2 Universidade de São Paulo, Programa de Pós-Graduação em Recursos Minerais e Hidrogeologia, fbdalmas@usp.br; 3 - Instituto Brasileiro do Meio Ambiente e Recursos Naturais Renováveis - IBAMA/MS, Divisão de Proteção Ambiental - DIPAM, joanice.battilani@ibama.gov.br)

\section{Resumo}

A obrigatoriedade do proprietário rural em recompor a área de reserva legal foi instituída pela Lei $n^{\circ}$ 8.171, de 17 de janeiro de 1991 e reiterada pela Medida Provisória no 2166-67, de 24 de agosto de 2001. No âmbito estadual, esta exigência manifesta-se através do Decreto $\mathrm{n}^{\circ}$ 11.700, de 8 de outubro de 2004 - que instituiu o Sistema de Recomposição, Regeneração e Compensação da Reserva Legal - e do Decreto $\mathrm{n}^{\circ}$ 12.528, de 27 de março de 2008 - que instituiu o Sistema de Reserva Legal no Estado de Mato Grosso e modificou o quantitativo mínimo de recomposição anual para pelo menos um doze avos da área total necessária à complementação da referida reserva. Diante da crescente preocupação com este tema, a existência de uma metodologia de monitoramento de projetos de recomposição de reserva legal é fundamental, e o uso do geoprocessamento por possibilitar a reunião de grande número de informações em curto espaço de tempo é promissor para que se alcance tal objetivo. Este estudo avaliou o andamento da recomposição de reservas legais em três propriedades rurais do Estado de Mato Grosso do Sul utilizando geotecnologias, concluindo que não houve a recomposição proposta nos respectivos projetos devido à: falta de isolamento das áreas propostas para regeneração; plantio de espécies exóticas nas áreas destinadas à regeneração; e ao aproveitamento das áreas então propostas para recomposição como áreas de pastagem.

\footnotetext{
Artigo recebido para publicação em 27 de Fevereiro de 2012

Artigo aprovado para publicação em 04 de Janeiro de 2013
} 


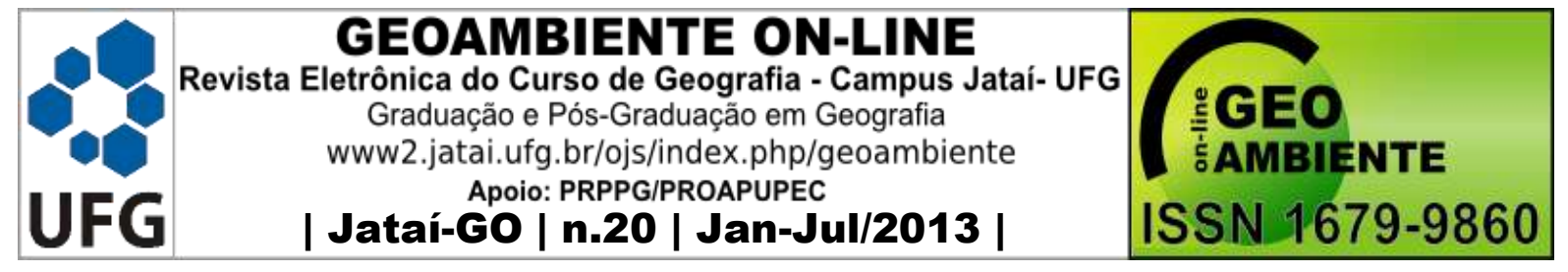

Palavras-chave: Sensoriamento Remoto, Imagens de Satélite, Recuperação Ambiental, Reserva Legal.

\section{Abstract \\ APPLICATION OF GEOTECHNOLOGIES IN THE MONITORING OF RECOMPOSITION PROJECTS OF LEGAL RESERVES}

The obligation of the landowner to recompose the legal reserve area was established by Federal Law No. 8171 of January 17, 1991 and reiterated by the Provisional Measure No. 2166-67 of August 24, 2001. At the state level, this requirement is manifested by Decree No. 11700 of October 8, 2004 - which established the System of Recomposition, Regeneration and Compensation of the Legal Reserve - and the Decree No. 12528 of March 27, 2008 which established the legal Reserve System in the State and changed the amount of minimum annual recomposition for at least one-twelfth of the total area required for the completion of this reserve. Given the growing concern about this issue, the existence of a monitoring methodology to projects for recomposing the legal reserve is essential, and the use of GIS by allowing the gathering of much information in a short space of time is promising for achieving such goal. This study evaluated the progress of the recomposition of legal reserves in three farms in the State of Mato Grosso do Sul using geotechnologies, concluding that there was no recomposition on their proposed projects due: to lack of isolation of the areas proposed for regeneration, the planting of exotic species in the areas for regeneration and recovery, and the utilization of the areas proposed for recomposition as grazing areas.

Keywords: Remote Sensing, Satellite Imagery, Environmental Restoration, Reserva Legal.

\section{Resumen}

\section{APLICACIÓN DE TECNOLOGÍAS SIG EN EL MONITOREO DE PROYECTOS DE RECOMPOSICIÓN DE RESERVA LEGAL}

La obligatoriedad de recuperar el área de Reserva Legal por parte del propietario de la tierra fue establecido por la Ley $\mathrm{n}^{\circ} 8.171$ del 17 de enero de 1991 y reiterado por la Medida Provisional $n^{\circ} 2.166-67$ del 24 de agosto de 2001. A nivel estatal, este requisito se manifiesta por el Decreto $\mathrm{N}^{\circ} 11.700$ del 8 de octubre de 2004 - que instituyó los Sistemas de Restauración, Regeneración y Compensación de la Reserva Legal - y el Decreto ${ }^{\circ} 12.528$ del 27 de marzo de 2008 - que estableció el Sistema de Reserva Legal en el Estado y ha cambiado 


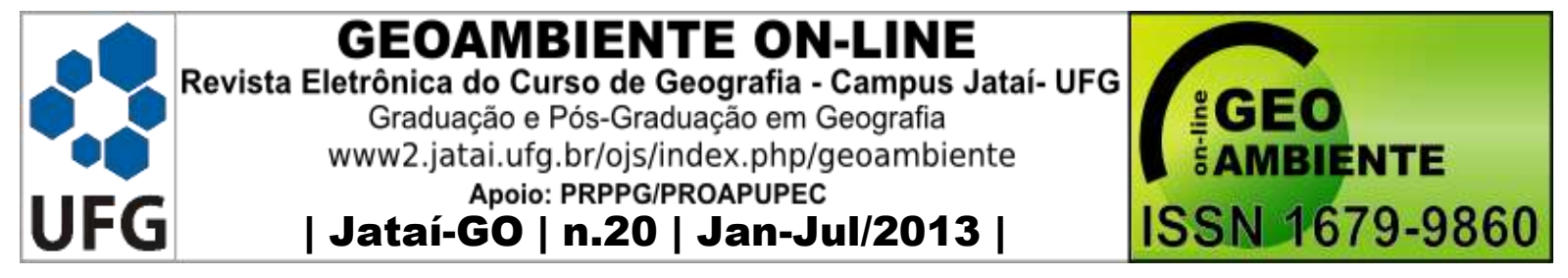

la cantidad de reposición anual mínima a una doceava parte de la superficie total existente, para la creación de esta reserva. Dada la creciente preocupación por esta cuestión, es esencial la existencia de un proyecto de metodología de monitoreo de la reconstrucción de la reserva legal basado en el uso de los SIG, permitiendo así el tratamiento de una gran cantidad de información en un corto espacio de tiempo. Este estudio evaluó el progreso de la restauración de las reservas legales en tres granjas dentro del Estado de Mato Grosso do Sul, concluyendo que no hubo recuperación en estas áreas debido a: aislamiento en las zonas propuestas para la regeneración, plantación de especies exóticas en las áreas destinadas a la regeneración, y la existencia de áreas de pastoreo en la superficie propuesta para su restauración.

Palabras-clave: Teledetección, Imagen de satélite, Recuperación del Medio Ambiente, Reserva Legal.

\section{1 - Introdução}

O Código Florestal Brasileiro, instituído por meio da Lei $\mathrm{n}^{\circ} 4.771$, de 15 de setembro de 1965 (Brasil, 1965), estabelece em seu art. 16º um limite mínimo de preservação de 20\% da área de florestas de domínio privado nas regiões Leste Meridional, Sul e Centro-Oeste (na parte sul). Posteriormente, a Medida Provisória no 2.166-67, de 24 de agosto de 2001 (Brasil, 2001), veio a acrescentar ao Código Florestal o conceito de Reserva Legal como "área localizada no interior de uma propriedade ou posse rural, excetuada a de preservação permanente, necessária ao uso sustentável dos recursos naturais, à conservação e reabilitação dos processos ecológicos, à conservação da biodiversidade e ao abrigo e proteção de fauna e flora nativas", retirando, pela primeira vez, o caráter utilitarista que o acompanhava e destacando sua função como área de conservação da biodiversidade (Joels, 2002).

A Medida Provisória acima reitera a obrigatoriedade do proprietário rural em recompor a reserva legal de sua propriedade mediante o plantio, a cada três anos, de no mínimo um décimo da área total necessária à sua complementação, com espécies nativas, de acordo com critérios estabelecidos pelo órgão ambiental estadual competente, que também tem a responsabilidade de avaliar a regeneração proposta e, em caso de comprovar a viabilidade por meio de laudo técnico, autorizá-la, podendo ser exigido o isolamento da área. Tal obrigatoriedade já havia sido instituída anteriormente pela Lei $\mathrm{n}^{\circ} 8.171$, de 17 de janeiro de 1991 (Brasil, 1991). 


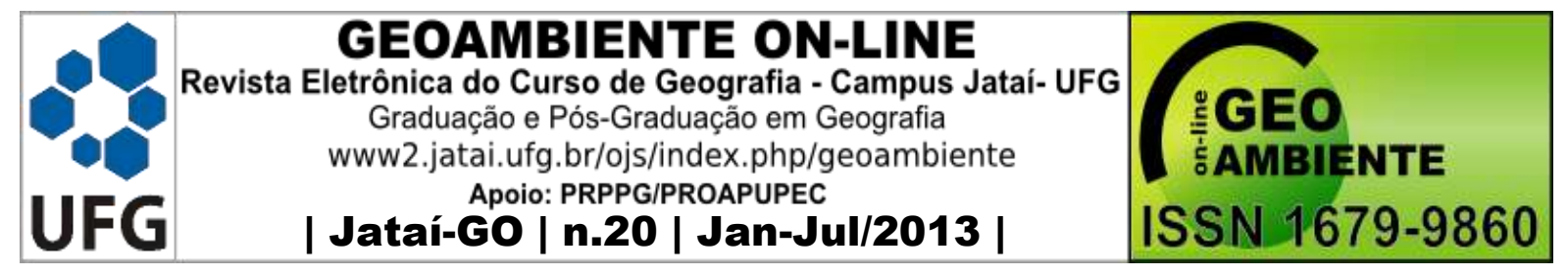

O processamento de tais modificações, tanto na dimensão quanto na finalidade do instrumento de gestão ambiental denominado Reserva Legal, revela a profunda guinada que a política pública deu em relação a esta questão e o conseqüente acirramento do debate sobre esta imposição legal. Pois, se antes havia incentivo ao desmatamento e à incorporação de áreas ao processo produtivo, com um viés de desenvolvimento sócio-econômico do país, que se revelava concreto através de programas tais como o POLOCENTRO e o PROVÁRZEAS, a posterior atribuição dos custos de conservação e manutenção ambiental das áreas de reserva legal aos proprietários rurais representou, para muitos agentes econômicos, um contra-senso. Entre estes agentes, a Confederação da Agricultura e Pecuária do Brasil (CNA, 2001), representante política dos empresários rurais questiona o fato de que esta responsabilidade gere encargos exclusivamente privados e benefícios sociais (Rigonatto e Nogueira, 2006).

Arana \& Baldassi (2006) citam que, no Estado do Paraná, os pequenos e médios proprietários, encarando a Reserva Florestal Legal como imobilização econômica de parte de suas propriedades e aproveitando a falta de condições de fiscalização em que se encontram os órgãos ambientais, acabam evitando a averbação da Reserva Legal por entenderem que esta área seria perdida em termos de produtividade rural. A falta de informação e de assessoria técnica por parte dos órgãos ambientais e de extensão rural aos produtores contribui para a estagnação do processo.

O enrijecimento da exigência de recomposição de reserva legal reflete-se também no Estado de Mato Grosso do Sul através do Decreto $n^{\circ}$ 11.700, de 8 de outubro de 2004 (Mato Grosso do Sul, 2004), que veio a lançar as diretrizes estaduais para o que foi promulgado nacionalmente, instituindo o Sistema de Recomposição, Regeneração e Compensação da Reserva Legal, objetivando garantir que o território do Estado tenha, no mínimo, o índice de $20 \%$ de cobertura vegetal nativa e estabelecendo o quantitativo mínimo de recomposição anual de um dezessete avos da área nativa faltante. Posteriormente, o Decreto $\mathrm{n}^{\circ} 12.528$, de 27 de março de 2008 (Mato Grosso do Sul, 2008) instituiu o Sistema de Reserva Legal (SISREL) no Estado e modificou o quantitativo mínimo de recomposição anual para pelo menos um doze avos da área total necessária à complementação da referida reserva.

As áreas de reserva legal são protegidas contra desmatamentos, podendo ser somente utilizadas sob o regime de manejo florestal. A reserva legal traz diversos benefícios aos ecossistemas, tais como (Aquino \& Oliveira, 2006): 


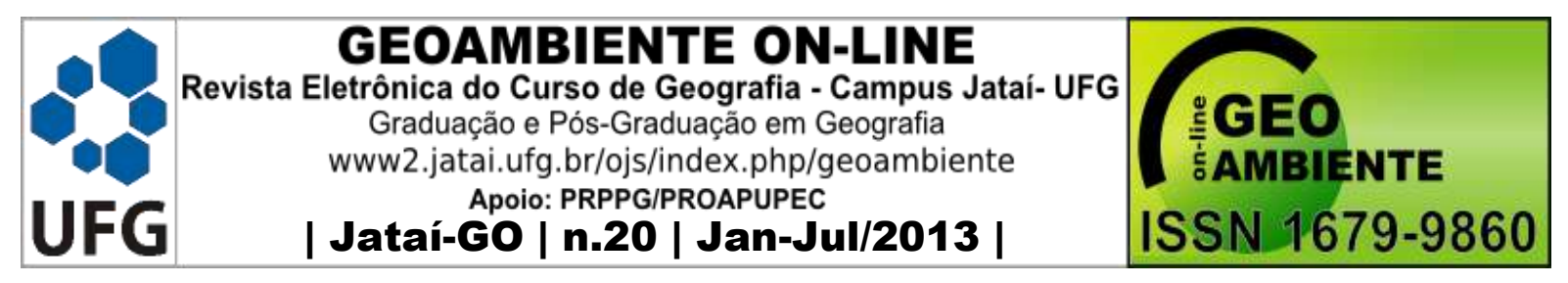

- Preservação dos recursos naturais;

- Abrigo e alimento para os animais;

- Proteção ao solo contra erosão e perda de nutrientes;

- Diminui o valor pago do Imposto sobre a Propriedade Territorial Rural - ITR;

- Permitir, mediante autorização, que o proprietário rural utilize a área de reserva legal de forma sustentável.

O trabalho de campo de fiscalização, considerando a extensão das áreas e o número de técnicos dos órgãos competentes insuficientes, pode ser uma atividade onerosa e morosa, o que dificulta o acompanhamento da evolução da transformação da paisagem (Silva Aparecida, 2005). Corroborando com essa afirmação, Xavier (2007) cita que a preservação ambiental requer maior fiscalização e com recursos tecnológicos para uma maior eficiência no monitoramento ambiental. Baseado nesta necessidade, o Sistema de Informações Geográficas (SIG) torna-se uma ferramenta eficaz de controle ambiental.

Nos resultados publicados por Azevedo (2009), evidencia que o uso do SIG contribui na delimitação de Reservas Legais. O autor trabalhou com 146 propriedades, no município de Extrema/MG, quando identificou que 22 propriedades possuem vegetação nativa para averbação de reserva legal, as outras 124 necessitam efetuar a recomposição. Assim, concluiu que a utilização de SIG é eficaz na delimitação, quantificação e caracterização de Reservas Legais.

Outra técnica também muito bem aplicada nos estudos ambientais é o Sensoriamento Remoto, que, por exemplo, possibilita identificar e analisar a cobertura vegetal através da energia eletromagnética refletida pelos alvos (Martins, 2009).

A existência de uma metodologia de monitoramento do processo de recomposição das áreas de reserva legal revela-se necessária e a aliança entre Geoprocessamento e Sensoriamento Remoto, por possibilitar a união de grande número de informações em curto espaço de tempo, constitui-se tecnologia imprescindível ao estudo e análise das variações terrestres (Baseggio et al., 2006), sendo promissora para que se alcance tal metodologia, principalmente através de imagens de satélites como os Landsat 5 e 7, CBERS 2 e 2B ou IRS, atualmente disponibilizadas de forma gratuita. A condução de tal monitoramento norteada pelo princípio da reunião e comparação de informações multitemporais revela-se de fundamental importância, estando em consonância com o exposto por Paranhos Filho (2000). 


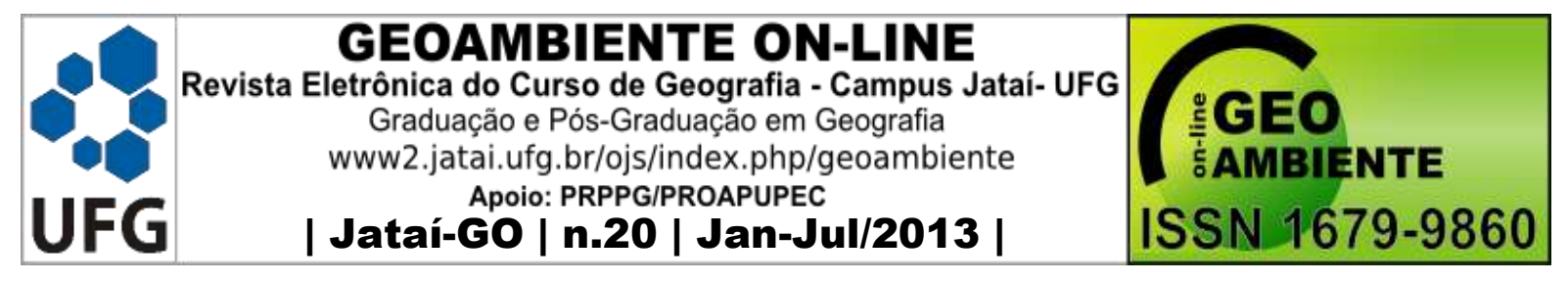

O objetivo desta pesquisa foi avaliar o estado atual de três projetos de recomposição de reserva legal deferidos pelo Instituto do Meio Ambiente e dos Recursos Naturais Renováveis do Mato Grosso do Sul (IBAMA/MS), confrontando esta avaliação com a situação destes projetos na data original de sua apresentação, bem como no ano de 1984.

$\mathrm{O}$ foco do trabalho foi executar um projeto-piloto dentro da rotina do IBAMA (Instituto Brasileiro de Meio Ambiente e dos Recursos Naturais), que entre 2007 e 2008, tinha muitos projetos de recomposição de reserva legal protocolados e encontravam-se praticamente "parados", por falta de contingente técnico. Assim, priorizou-se que os projetos não fossem tão recentes, exatamente para verificar se algo havia sido feito pelos proprietários e responsáveis técnicos que elaboraram os projetos. Também buscou-se visitar propriedades não tão afastadas da capital, para facilitar a logística toda do trabalho.

\section{2 - Material e métodos}

\section{1 - Área de estudo}

A área de estudo é composta por três propriedades rurais, que foram escolhidas para a validação dos dados de laboratório considerando-se o regime de trabalho de fiscalização no IBAMA de Campo Grande, MS e haver o consentimento dos proprietários em permitir a utilização dos dados em trabalho científico. Tais áreas apresentam como principal atividade econômica a agropecuária e localizam-se nas cenas de órbita/ponto CBERS-2B, sensor CCD, 162/123, 163/122 e 163/123, conforme Figura 1. De acordo com os mapas de Biomas (IBGE, 2004) e Vegetação (IBGE, 2002) todas as propriedades estudadas inserem-se na área do bioma Cerrado e caracterizam-se como áreas antropizadas.

a) Fazenda 1

A primeira área analisada foi uma fazenda localizada no Município de Jaraguari e teve seu projeto de recomposição de reserva legal apresentado ao Instituto Brasileiro do Meio Ambiente e dos Recursos Naturais Renováveis (IBAMA/MS) em fevereiro de 1999, com posterior deferimento em janeiro de 2001, situando-se a sede à latitude de 20 02' 58" Sul e longitude de $54^{\circ} 15^{\prime} 43^{\prime \prime}$ Oeste. A área da propriedade constante no projeto é de 2.619,15 hectares e a área objeto do projeto de recomposição de reserva legal é de 184,25 hectares, sendo 69,83 hectares a serem recuperados por reflorestamento, durante 22 anos e 114,42 hectares a serem recuperados por processo de regeneração natural, com isolamento da área. 


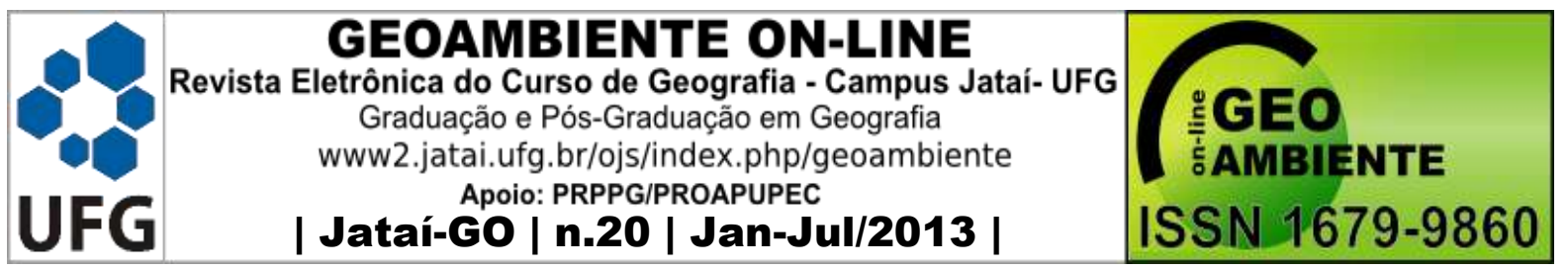

As imagens de satélite submetidas à fotointerpretação e posterior vetorialização das áreas objeto do monitoramento são as cenas de órbita/ponto 224/74, do satélite Landsat 5, sensor TM, das datas de 2 de julho de 1984 e 7 de abril de 1999 (Landsat, 1984a e Landsat, 1999), além da cena 163/122 do sensor CCD do satélite CBERS-2B de 4 de agosto de 2008 (CBERS, 2008a).

Figura 1 - Localização das áreas de estudo na grade CBERS e os municípios que abrangem seus perímetros.

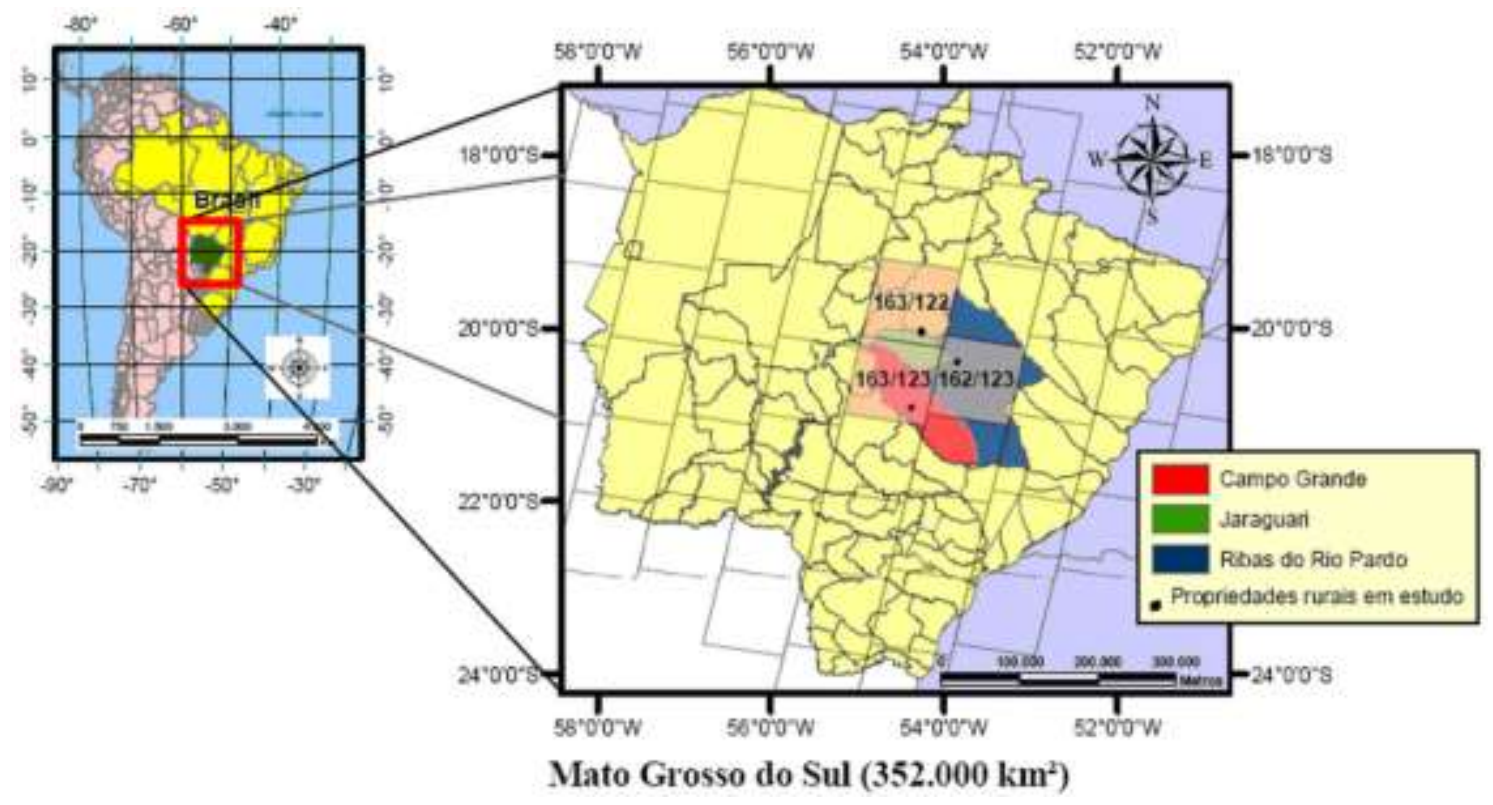

b) Fazenda 2

A segunda fazenda localiza-se no Município de Campo Grande e teve seu projeto de recomposição de reserva legal apresentado ao IBAMA/MS em junho de 2000, com posterior deferimento em julho de 2002, situando-se a sede à latitude $20^{\circ} 55^{\prime} 27^{\prime \prime}$ Sul e longitude $54^{\circ} 23^{\prime}$ 03" Oeste. A área da propriedade constante no projeto é de 597,22 hectares e a área objeto do projeto de recomposição de reserva legal é de 50 hectares, a ser recomposta durante um período de três anos, a partir do deferimento, por processo de regeneração natural.

As imagens de satélite submetidas à fotointerpretação e posterior vetorialização das áreas objeto do monitoramento são as cenas de órbita/ponto 224/075, do satélite Landsat 5, sensor TM, das datas de 2 de julho de 1984 e 11 de maio de 2000 (Landsat, 1984b e Landsat, 2000a), além da cena 163/123 do sensor CCD do satélite CBERS 2B de 4 de agosto de 2008 (CBERS, 2008b). 


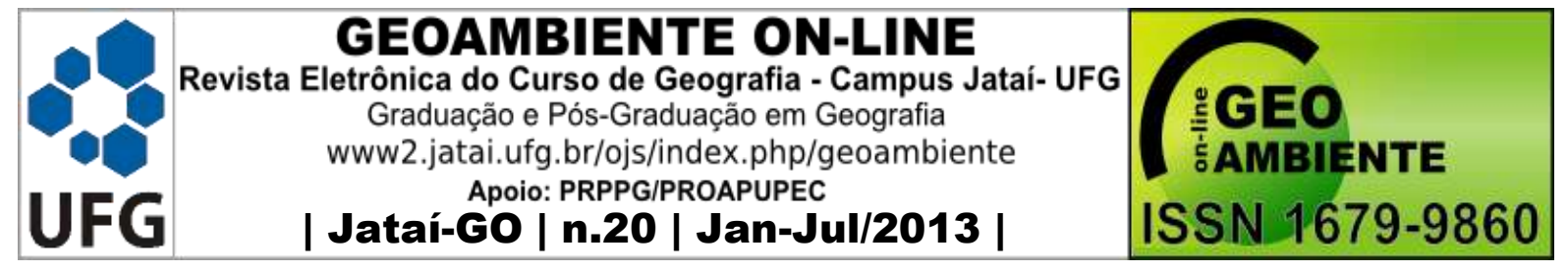

c) Fazenda 3

A outra fazenda estudada localiza-se no Município de Ribas do Rio Pardo e teve seu projeto de recomposição de reserva legal apresentado ao IBAMA/MS em outubro de 2000, com posterior deferimento em dezembro de 2003, situando-se a sede à latitude 20 23' 48" Sul e longitude $53^{\circ} 50^{\prime} 45^{\prime \prime}$ Oeste. A área da propriedade constante no projeto é de 1.224,21 hectares e a área objeto do projeto de recomposição de reserva legal é de 155 hectares, que seria isolada e recomposta pelo processo de regeneração natural, durante o período de dois anos a partir do deferimento, com posterior enriquecimento, se necessário.

As imagens de satélite submetidas à fotointerpretação e posterior vetorialização das áreas objeto do monitoramento são as cenas de órbita/ponto 224/074, do satélite Landsat 5, sensor TM, das datas de 2 de julho de 1984 e 11 de maio de 2000 (Landsat, 1984a e Landsat, 2000a), além da cena 162/123 do sensor CCD do satélite CBERS 2B de 12 de julho de 2008 (CBERS, 2008c).

Para o desenvolvimento da metodologia de monitoramento designou-se como fonte das imagens de satélite o catálogo digital gratuito da Divisão de Geração de Imagens (DGI, 2008) do Instituto Nacional de Pesquisas Espaciais (INPE), que pode ser acessado através endereço http://www.dgi.inpe.br/CDSR/.

Justifica-se a escolha das imagens já mencionadas no item anterior pela necessidade de se comparar, para cada propriedade, a situação da vegetação na época atual; na época de apresentação do projeto e na data mais antiga possível, considerando a fonte de imagens já referida.

Realizou-se o pré-processamento das nove imagens adquiridas para que se evitassem deslocamentos que poderiam prejudicar os próximos passos da análise e desqualificar resultados. Para tal, a base de referência foi composta por imagens do satélite Landsat 7/ ETM+ (Enhanced Thematic Mapper Plus) 224/074 e 224/075, ortorretificadas, de 6 de maio de 2001, disponibilizadas pela Global Land Cover Facility (GLCF, 2008) através do seu site (http://www.landcover.org/index.shtml). Estas imagens integram o Mosaico Geocover Landsat da Agência Espacial Norte-Americana (NASA, 2005) e seu uso no georreferenciamento de imagens de satélite foi avaliado por Stefanes et al. (2005), apresentando resultados satisfatórios. 


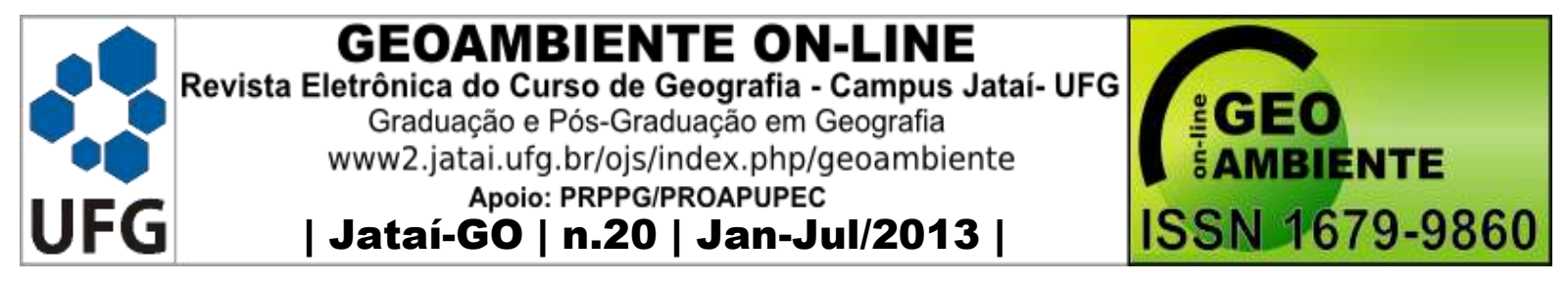

O georreferenciamento foi realizado utilizando-se o software ERDAS Imagine (ERDAS, 2006), adotando a projeção Universal Transversa de Mercator (UTM) e o datum South American 1969 Mean Solution (SAD 69).

As imagens Landsat 7/ETM+ ortorretificadas apresentam resolução espacial de 14,25 metros, obtida com suporte do software ERDAS Imagine (ERDAS, 2006), que permite a realização de fusão do arquivo multiespectral (de bandas 1, 2, 3, 4, 5 e 7, então com resolução de 28,5 metros) com a banda 8 , pancromática, de resolução espacial de 14,25 metros. As imagens Landsat 5/TM possuem resolução espacial de 30 metros, enquanto as imagens CBERS-2B/CCD, por sua vez, possuem resolução espacial de 20 metros.

De acordo Lilesand et al. (2004), a reflectância da vegetação saudável aumenta consideravelmente na porção do infravermelho próximo do espectro eletromagnético, que compreende comprimentos de onda de cerca de $0,7 \mu \mathrm{m}$. Considerando que no sensor TM do Landsat 5 a banda espectral que fornece as informações mais próximas desta faixa do espectro é a banda 4, verificando-se o mesmo para a banda 4 do sensor CCD do CBERS-2B, optou-se pela composição de bandas 453 para todas as imagens Landsat em estudo, e pela composição 423 para todas as imagens CBERS.

Os perímetros das propriedades rurais foram então digitalizados, com auxílio do software GPS TrackMaker PRO 4.4 (Ferreira Júnior, 2008), tomando-se por base as cópias das matrículas e os mapas constantes nos respectivos processos, de posse do IBAMA. Esta etapa, particularmente, foi alvo da falta de informações mais precisas constantes nos documentos.

Com o banco de dados formado, foi possível realizar a fotointerpretação das imagens de satélite e quantificar as áreas de vegetação com características que permitiam a sua inclusão ao conceito de reserva legal. As características naturais de cada propriedade levaram à necessidade de também fotointerpretar e vetorializar os cursos hídricos (lagos, lagoas, açudes) e áreas de preservação permanente para que não houvesse risco de superposição de resultados. De acordo com as imagens de satélite as propriedades estudadas apresentam topografia plana, sem ocorrência de elevações que determinem a existência de áreas de preservação permanente de morros ou montanhas, desta forma, as áreas de preservação permanente vetorializadas restringiram-se à hidrografia (este dado foi confirmado posteriormente com o trabalho realizado a campo). 


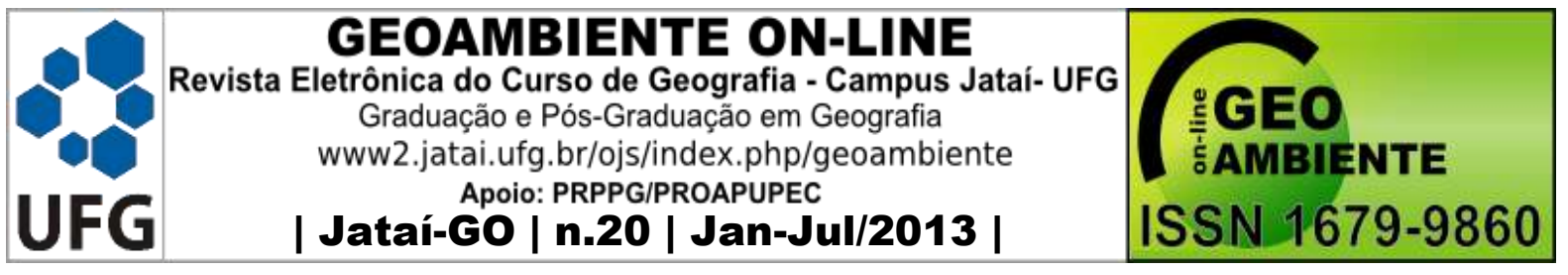

Este conjunto de operações foi realizado através do software Geomatica Focus (PCI, 2003) e, após a fotointerpretação, traduziu-se na seguinte seqüência (Figura 2): vetorialização dos cursos hídricos, reservatórios e açudes localizados nas propriedades; geração dos buffers que caracterizam as áreas de preservação permanente de hidrografia; vetorialização das áreas cuja vegetação se enquadre no conceito de reserva legal e exclusão dos polígonos que se sobrepunham aos de áreas de preservação permanente. Para esta etapa, o uso da banda 8 (pancromática) das imagens Landsat 7/ETM+ foi de fundamental importância, principalmente no que se refere à digitalização dos rios e córregos, devido a sua melhor resolução espacial $(14,25$ metros).

Figura 2 - Vetorialização dos cursos hídricos, em azul (i), definição das áreas de preservação permanente, em amarelo (ii), vetorialização das áreas cuja vegetação se enquadre no conceito de reserva legal, em vermelho (iii) e exclusão dos polígonos que se sobrepunham aos de áreas de preservação permanente (iv).

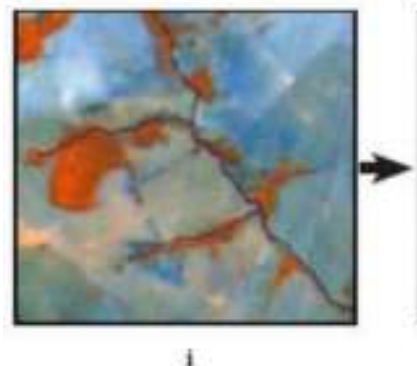

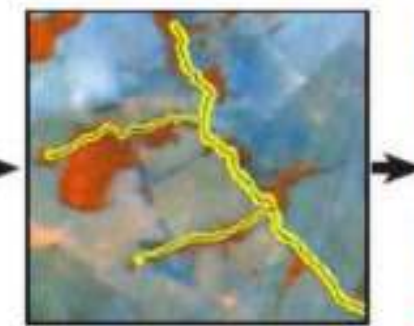

if

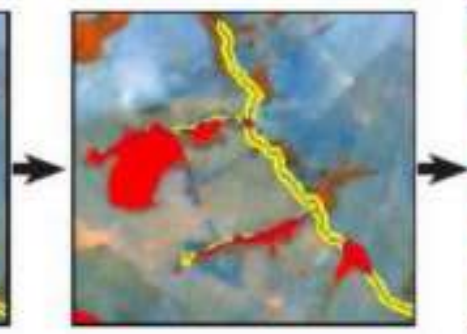

iif

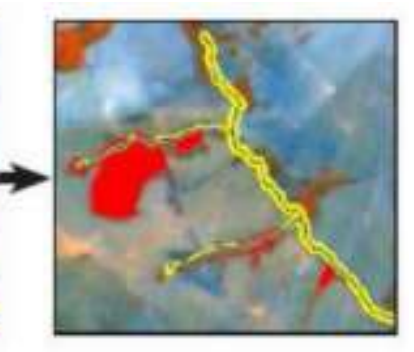

iv

O passo seguinte constituiu-se da exclusão dos polígonos de vegetação característica de reserva legal com área inferior a cinco hectares que estivessem localizados de forma isolada, circundados por pastagens ou sem ligação direta com áreas de preservação permanente, o que não possibilita a formação de corredores ecológicos. A realização desta etapa encontra respaldo na Teoria de Biogeografia de Ilhas (MacArthur e Wilson, 1967), que, entre seus princípios, afirma ocorrer aumento da biodiversidade com o aumento do tamanho de um fragmento de mata nativa e diminuição da biodiversidade com o aumento da distância para o fragmento mais próximo ou outra fonte de espécies.

Os dados obtidos em ambiente SIG, foram, então, validados através do trabalho realizado a campo, em parceria com o IBAMA/MS, que possibilitou a aquisição de trilhas e coordenadas das áreas em estudo com o auxílio do GPS Garmin GPSMAP 60CSx (Garmin, 2006), além das informações registradas através de fotografias e vídeos. As coordenadas e trilhas obtidas foram transferidas para o banco de dados já existente através do software GPS TrackMaker PRO 4.4 (Ferreira Júnior, 2008) e, juntamente com as fotografias e vídeos, 


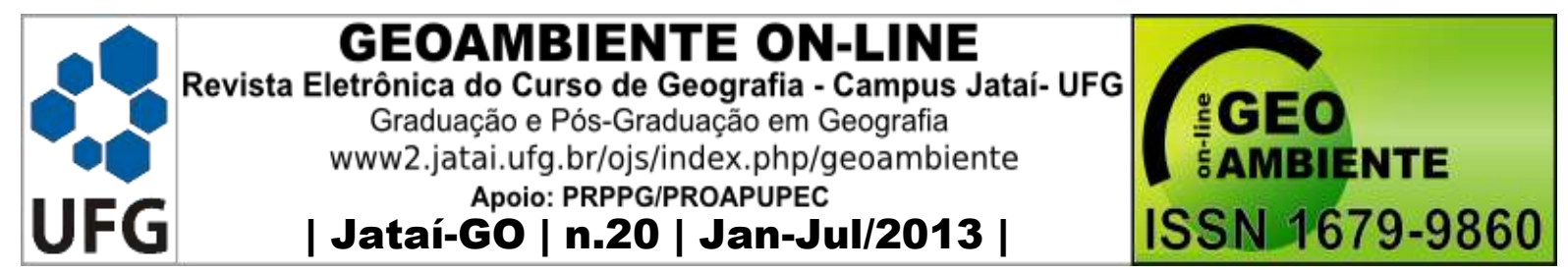

contribuíram para avaliar a qualidade e precisão do pré-processamento e da fotointerpretação das imagens de satélite.

A geração de layouts com os produtos finais foi realizada com o software ArcMap 9.1 (ESRI, 2005).

\section{3 - Resultados e discussão}

A sobreposição dos perímetros, digitalizados com base nos documentos de cada propriedade, com as imagens Landsat 7/ETM+ ortorretificadas, revelou que os limites e valores observados para as áreas totais não condiziam totalmente com os mostrados pelas imagens. Isto levou à necessidade de correções destes vetores, resultando em alterações dos valores das áreas, como se pode verificar nos itens abaixo.

a) Fazenda 1

A área total quantificada para Fazenda 1, considerando o perímetro digitalizado a partir dos documentos da propriedade, foi de 2.617,55 hectares.

Na Figura 3 é apresentado os resultados da análise da propriedade, feita através de fotointerpretação e vetorialização sobre imagem do satélite Landsat 5, 224/074, sensor TM, de 2 de julho de 1984, apresentando um valor de 131,17 hectares para áreas que se enquadrariam ao conceito de reserva legal, e 154, 11 hectares em abril de 1999 (Figura 4) . 


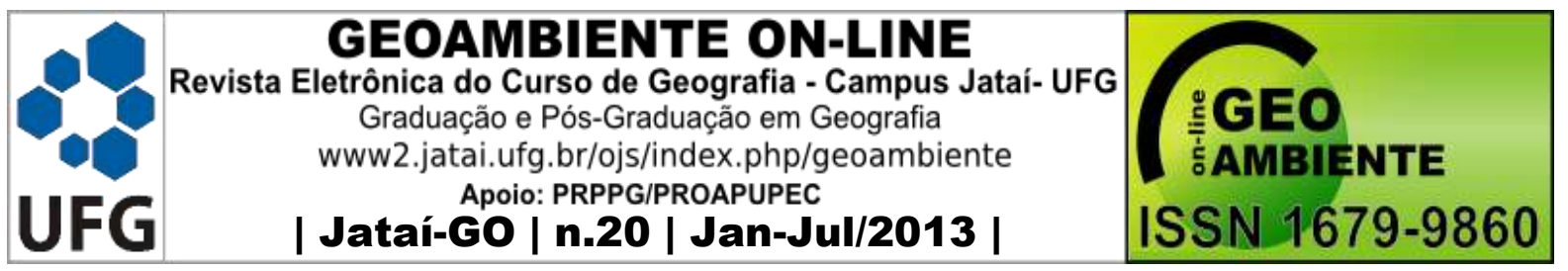

Figura 3 - Análise da área da fazenda 1, em julho de 1984, realizada sobre imagem Landsat5 (órbita 224/74), sensor TM, projeção UTM, fuso 22, datum SAD 69 e composição RGB 453.

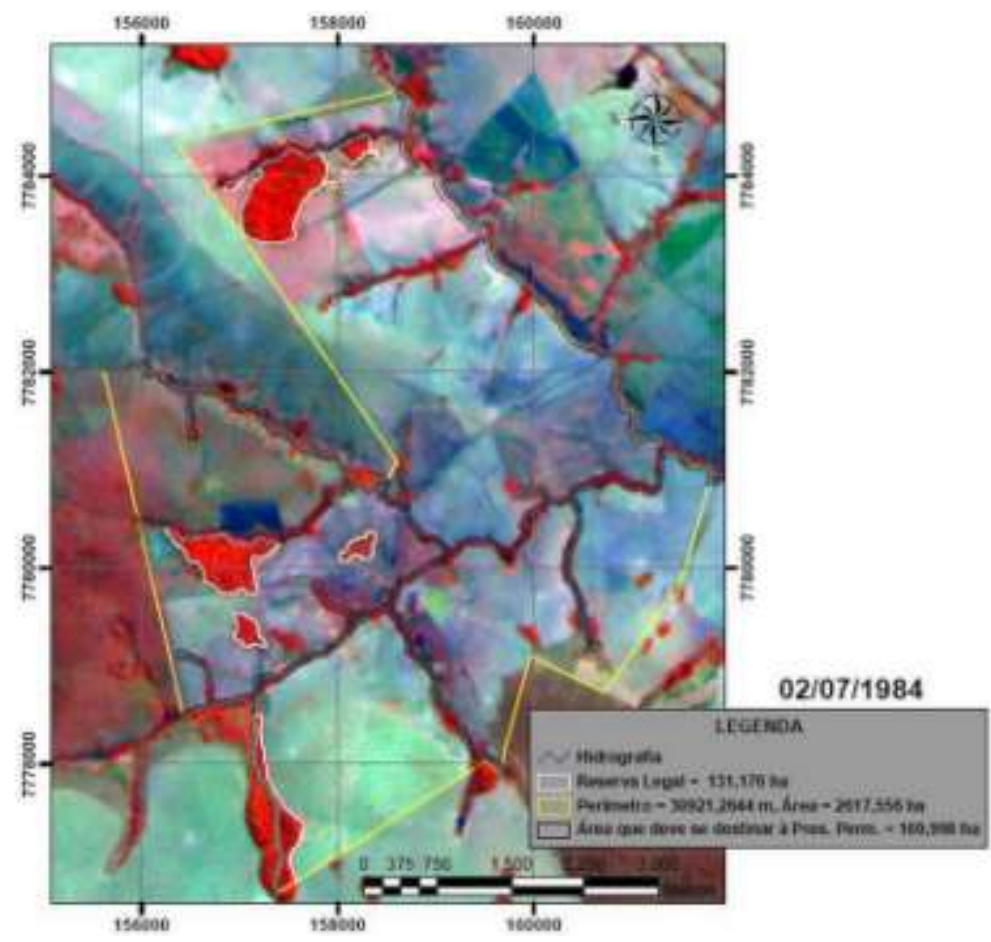

Figura 4 - Resultados da vetorização das áreas de Reserva Legal da fazenda 1, em abril de 1999, através de imagem Landsat5 (órbita 224/74), sensor TM, projeção UTM, fuso 22, datum SAD 69 e composição RGB 453.

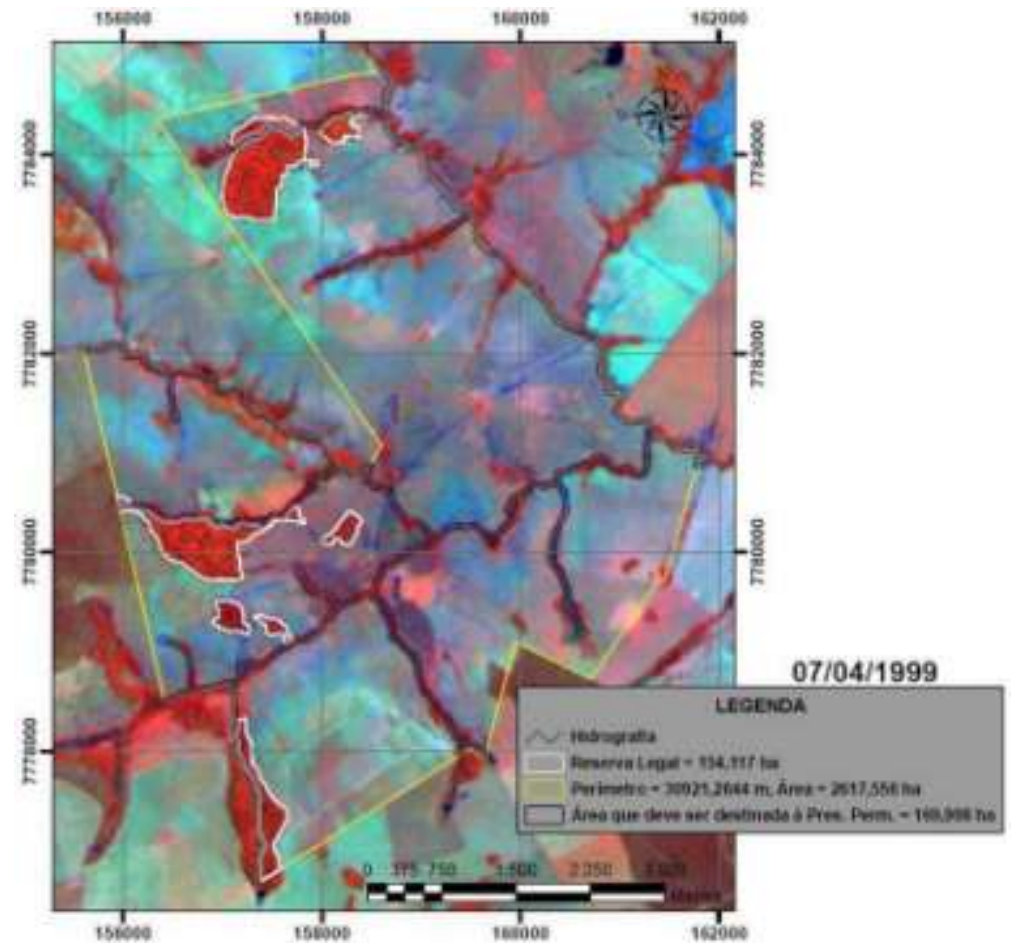




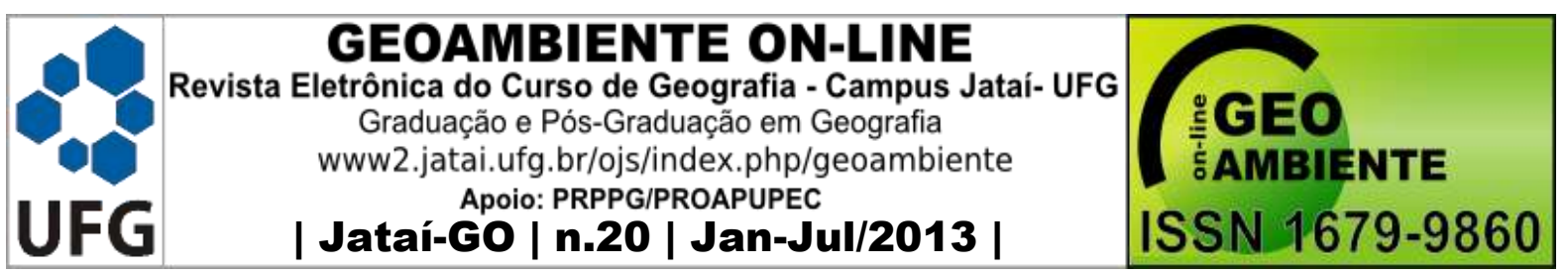

A Figura 5 apresenta a mesma análise aplicada à situação atual, através de fotointerpretação e vetorialização sobre imagem do satélite CBERS-2B/CCD, 163/122, de 4 de agosto de 2008, apresentando valor de 179,05 hectares (6,84\% da área total) para áreas cujas características se adéqüem aos preceitos de reserva legal.

Figura 5 - Análise da área compreendida pela fazenda 1 através de imagem do satélite CBERS 2B/CCD (órbita 163/122), projeção UTM, fuso 21, datum SAD 69 e composição RGB 423, de agosto de 2008.

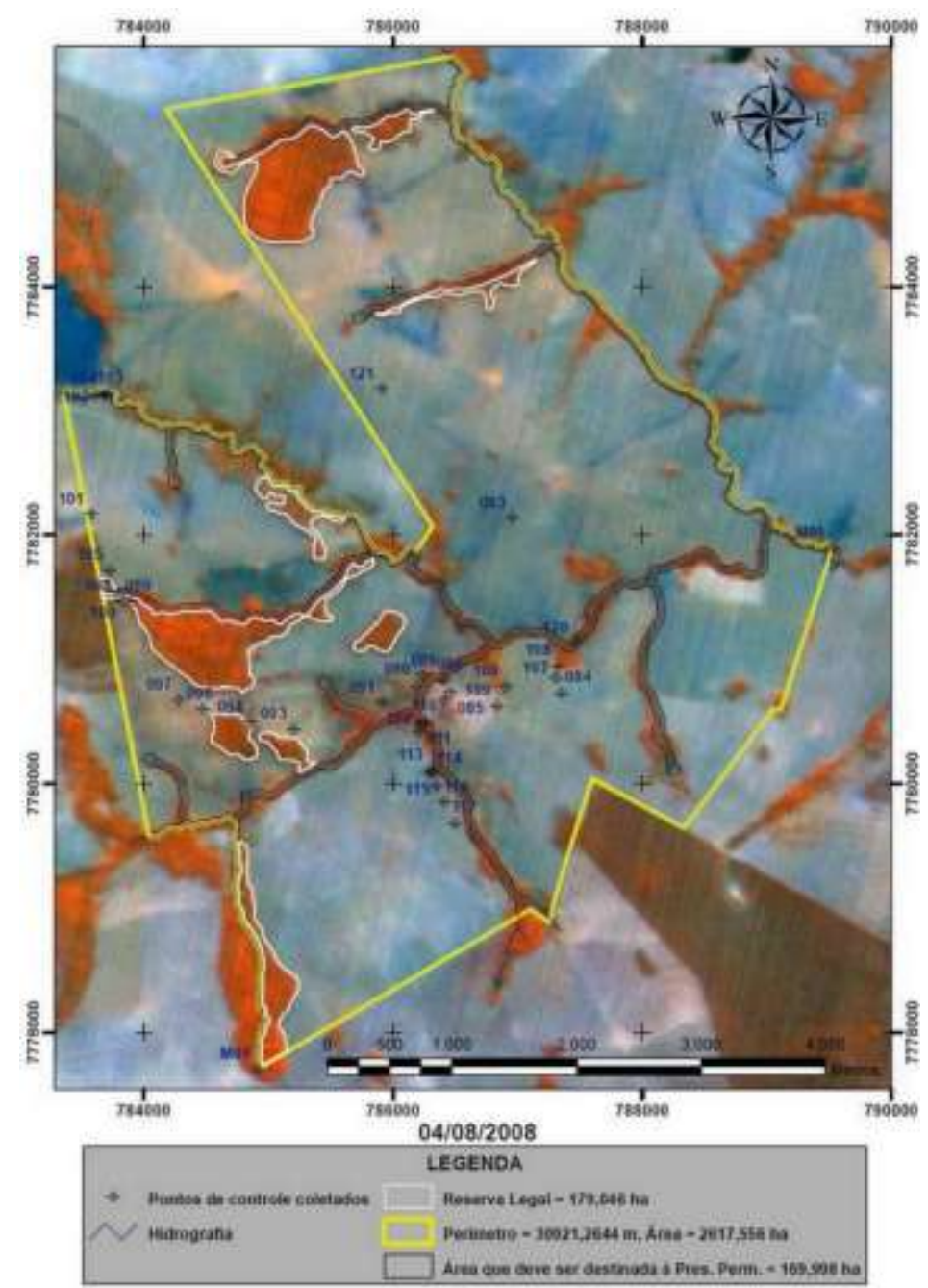




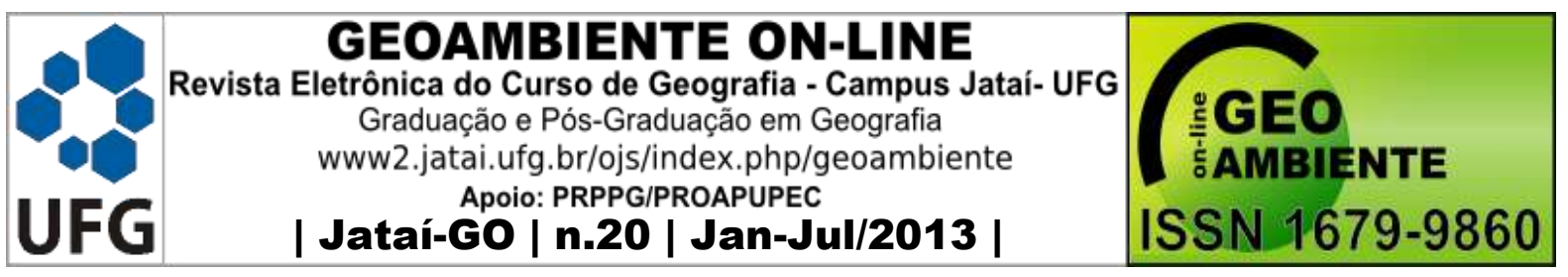

b) Fazenda 2

No caso da Fazenda 2, verificou-se que, entre a data de deferimento do projeto de recomposição de reserva legal e a atualidade, houve uma modificação dos limites da propriedade devido à anexação de área vizinha.

Portanto, as análises feitas para os anos de 1984 e 2000 consideram a antiga área, denominada, na época, de Gleba “A”. Para estes dois casos, a área total quantificada, após as devidas correções sobre o perímetro digitalizado a partir dos documentos da propriedade, foi de 607 hectares. Já a análise da situação atual considerou também a área anexada posteriormente, apresentando um valor de 817,92 hectares para a área total da propriedade. A Figura 6 mostra os resultados da análise feita com imagem Landsat 5, 224/075, sensor TM, de 2 de julho de 1984, apresentando como resultado o valor de 222,69 hectares para áreas que se enquadraram ao conceito de reserva legal.

Figura 6 - Análise realizada com imagem Landsat5 (órbita 224/75), sensor TM, projeção UTM, fuso 22, datum SAD 69 e composição RGB 453, de julho de 1984.

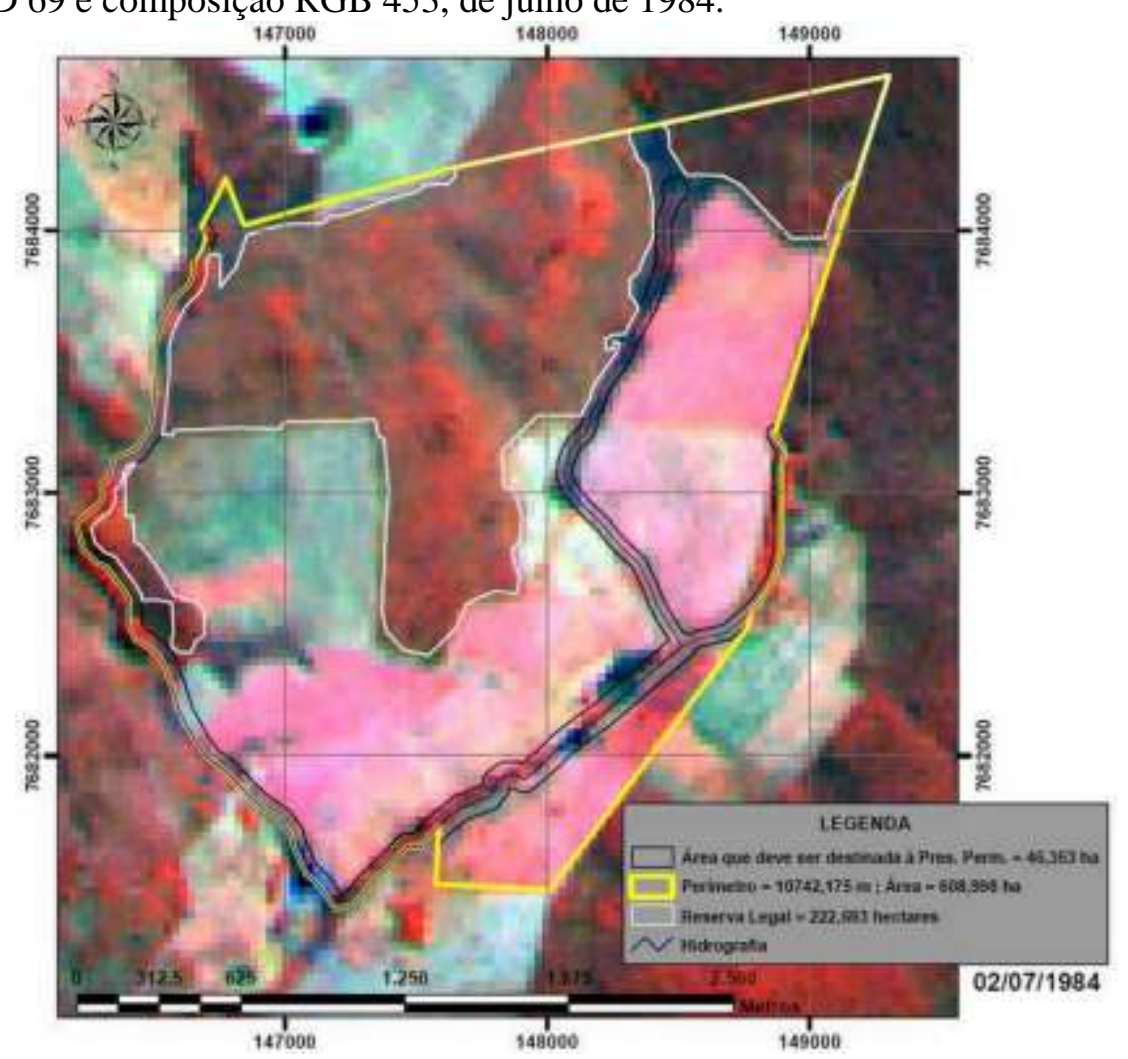




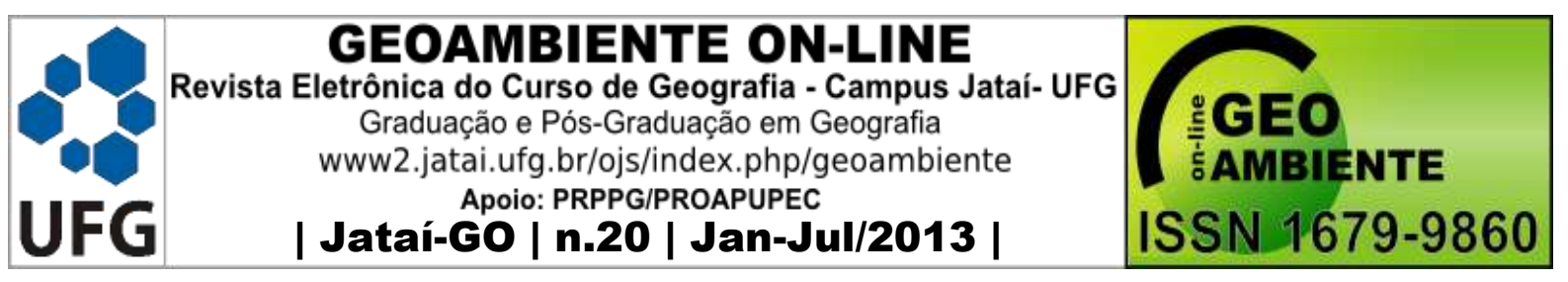

Na Figura 7 encontram-se os resultados da análise feita com imagem Landsat 5, 224/075, sensor TM, de 11 de maio de 2000, apresentando como resultado o valor de 47,87 hectares para áreas que se enquadrariam ao conceito de reserva legal.

A Figura 8, por fim, apresenta a análise aplicada à situação atual, através de vetorialização sobre imagem do satélite CBERS-2B/CCD, 163/123, de 4 de agosto de 2008, resultando em um valor de 93,77 hectares $(11,46 \%$ da área total) para áreas cujas características sejam compatíveis com o conceito de reserva legal.

Figura 7 - Análise realizada com imagem Landsat5 (órbita 224/75), sensor TM, projeção UTM, fuso 22, datum SAD 69 e composição RGB 453, de maio de 2000.

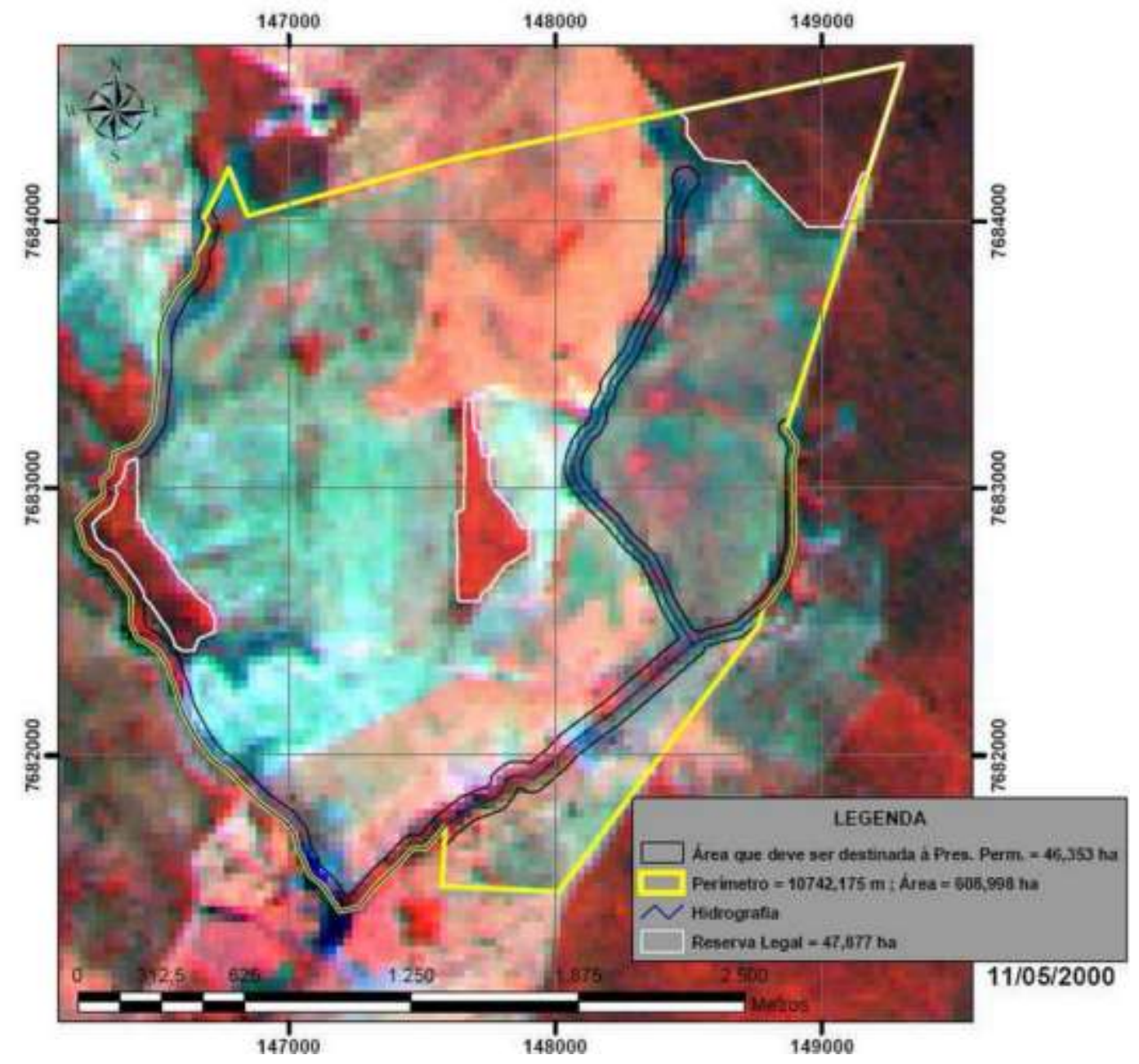




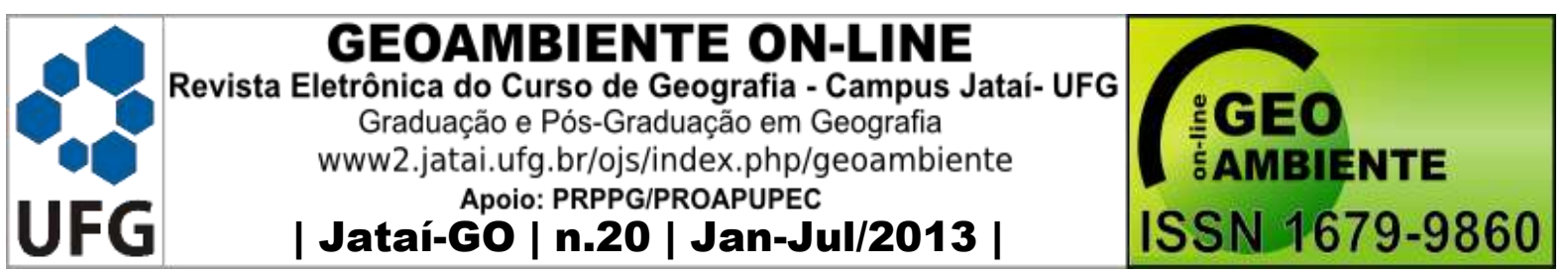

Figura 8 - Análise da área compreendida pela fazenda 2 através de imagem do satélite CBERS2B/CCD (órbita 163/123), projeção UTM, fuso 21, datum SAD 69 e composição RGB 423, de agosto de 2008.

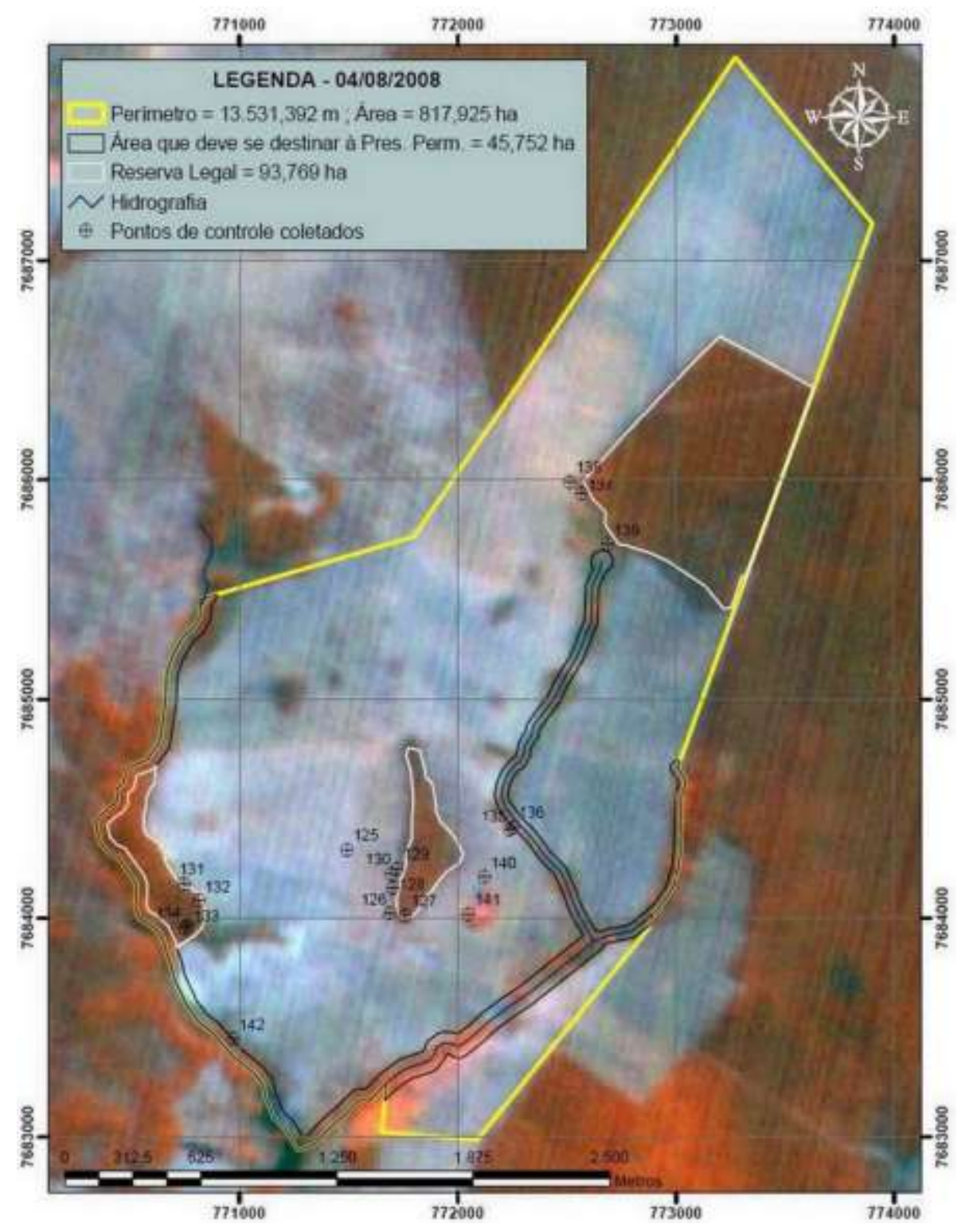

c) Fazenda 3

A Figura 9 mostra os resultados da análise feita com imagem Landsat 5, 224/074, sensor TM, de 2 de julho de 1984, para o caso da Fazenda 3, apresentando o valor de 96,18 hectares para áreas que se enquadrariam ao conceito de reserva legal. 


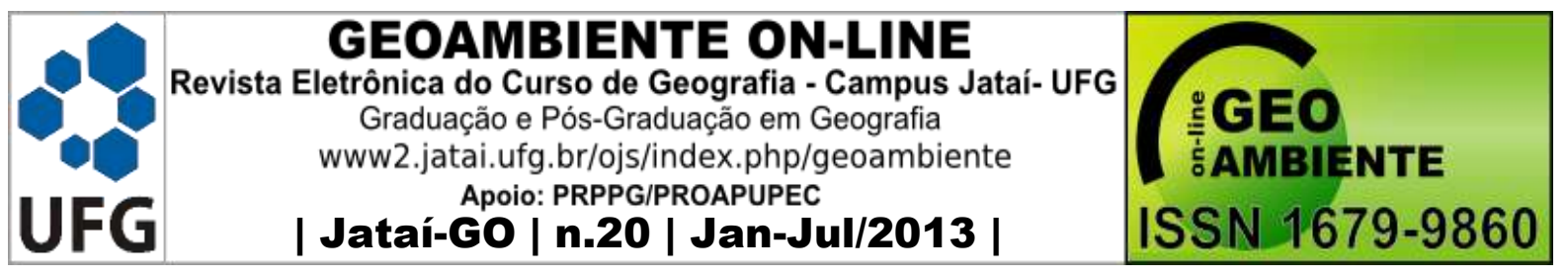

Figura 9 - Análise realizada com imagem Landsat5 (órbita 224/74), sensor TM, projeção UTM, fuso 22, datum SAD 69 e composição RGB 453, de julho de 1984.

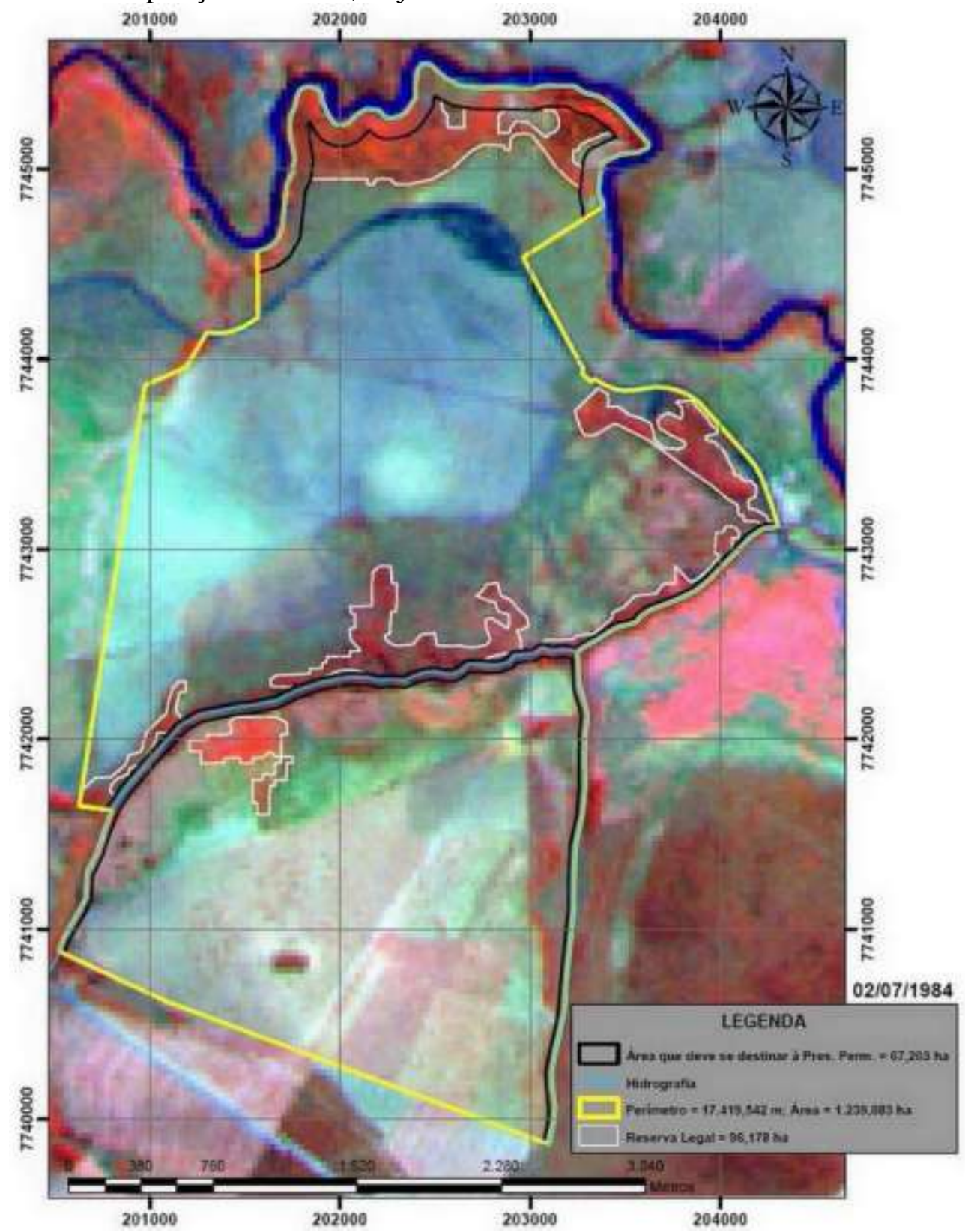

Na Figura 10 encontram-se os resultados da análise feita com imagem Landsat 5, 224/074, sensor TM, de 11 de maio de 2000, apresentando o valor de 94,40 hectares para áreas que se enquadrariam ao conceito de reserva legal. 


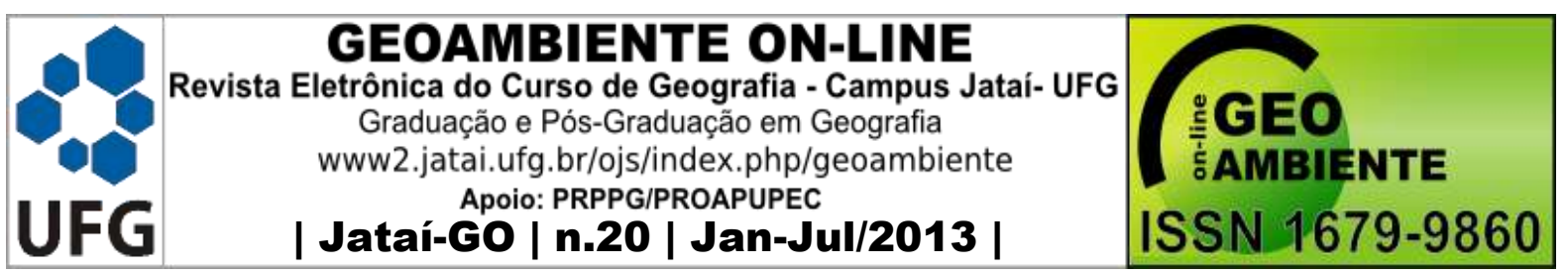

Figura 12 - Resumo da mudança cronológica referente às áreas de Reserva Legal das Fazendas 1, 2 e 3.

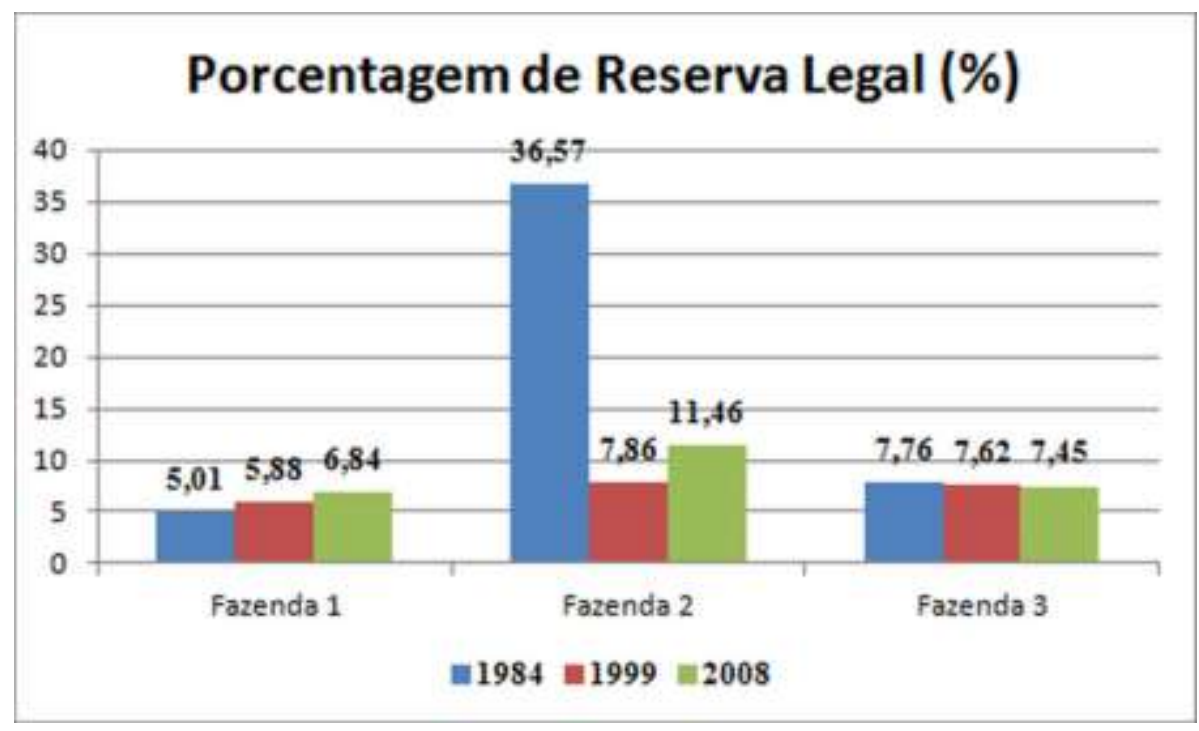

\section{Discussões}

Entre os procedimentos já apresentados justifica-se a adoção das imagens do sensor TM (Landsat 5), datadas de 1984, pela necessidade de avaliar se os problemas culminantes na apresentação dos projetos de recomposição já se manifestavam há mais de duas décadas nestas mesmas áreas, mesmo que o Código Florestal (BRASIL, 1965), instituído desde 1965, já vigorasse nesta época. Outro fator importante para esta escolha é o de que estas imagens puderam ser obtidas gratuitamente, além das mesmas não apresentarem grandes diferenças de resolução espacial das demais.

A análise visual das imagens TM (Landsat 5) de 1984 responde a dúvida manifestada no parágrafo anterior, pois todas as áreas já apresentavam algum grau de antropização. Apenas a fazenda 2, considerando sua antiga área, apresentava um percentual de áreas que podem ser consideradas como Reserva Legal superior aos $20 \%$ mínimos, totalizando na época 222,69 hectares, que no ano de 2000 já se encontravam drasticamente reduzidos a 47,87 hectares, apenas $7,86 \%$ da área total. Nos outros dois casos, verificou-se para a fazenda 1 , neste mesmo intervalo de tempo, um pequeno aumento percentual decorrente do acréscimo de 22,94 hectares em um período de 15 anos, totalizando, em 1999, 5,88\% de Reserva Legal; enquanto que, para a fazenda 3, de 1984 a 2000 ocorreu o decréscimo de 1,77 hectares, totalizando apenas 7,62\% de área que pudesse ser classificada como Reserva Legal, em 2000. 


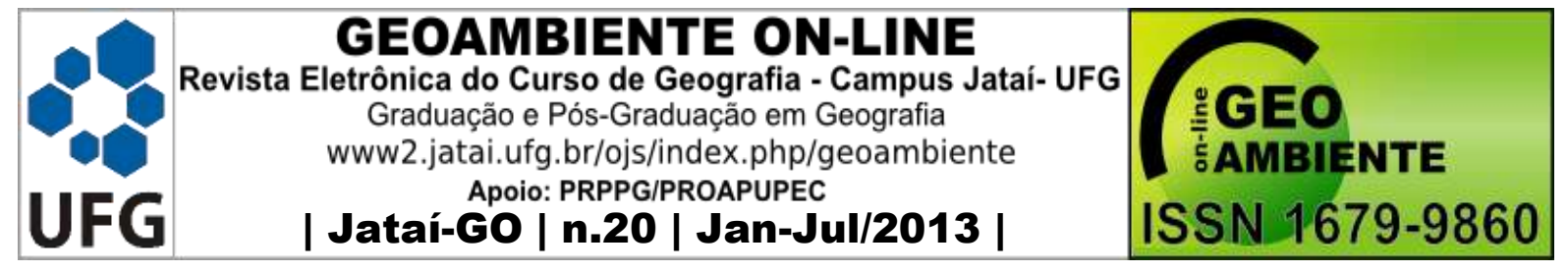

Estendendo a análise para o período existente entre a data de entrega dos projetos de recomposição e a situação atual, observa-se que apenas para a fazenda 1 e para a fazenda 2 houve aumento da porcentagem de Reserva Legal, embora os valores atuais ainda estejam muito distantes dos declarados em seus respectivos projetos. A única propriedade que apresentou um aumento superior a dois pontos percentuais, neste intervalo de tempo, foi a fazenda 2 , e isto se deu mais pela incorporação de uma nova área à propriedade, que contava com um grande fragmento de mata nativa, ao invés da implementação das técnicas descritas no projeto. A situação atual caracteriza-se, portanto, de acordo com a Figura 13: por 6,84\% de área que pode ser considerada como Reserva Legal para a fazenda $1 ; 11,46 \%$ para a fazenda 2 e 7,45\% para a fazenda 3, onde a situação manteve-se praticamente estável, estando sempre abaixo do percentual exigido.

A distância entre os valores observados atualmente e os pretendidos nos projetos de recomposição explica-se pelos fatores observados nas visitas a campo e retratados entre os resultados. Como contribuintes decisivos para o impedimento de alcance do percentual mínimo requerido pela legislação estão: a falta de isolamento das áreas propostas para regeneração e a conseqüente entrada de gado nas mesmas; o plantio de espécies exóticas em áreas destinadas à regeneração, o que muitas vezes resulta em competição na qual vence a espécie exótica; o aproveitamento das áreas então propostas para recomposição como áreas de pastagem.

Analisando a metodologia de estudo aqui descrita em relação à atual discussão sobre o novo Código Florestal, apresentado através da Lei N ${ }^{\circ} 12.727$, de 17 de outubro de 2012 (Brasil, 2012), pode-se observar alguns pontos que só poderão ser definitivamente constatados quando a reforma do Código passar a vigorar efetivamente: a proposta de reforma do Código florestal estabelece um maior escalonamento nas larguras de faixas de área de preservação permanente (APP) a serem respeitadas - em vários casos, a obrigatoriedade de preservação seria abrandada, considerando faixas com larguras inferiores a 30 metros. Diante desta situação, buscando-se evitar erros na identificação e distinção de polígonos de áreas de preservação permanente, e, por consequência, erros relativos à quantificação de vegetação com características de Reserva Legal que esteja localizada contiguamente a estas áreas, haveria necessidade de imagens de satélite com maior resolução espacial, cujo acesso e disponibilidade não costumam ser gratuitos. Este raciocínio também vale para os casos em que a obrigatoriedade de recomposição de áreas de preservação permanente e até mesmo de 


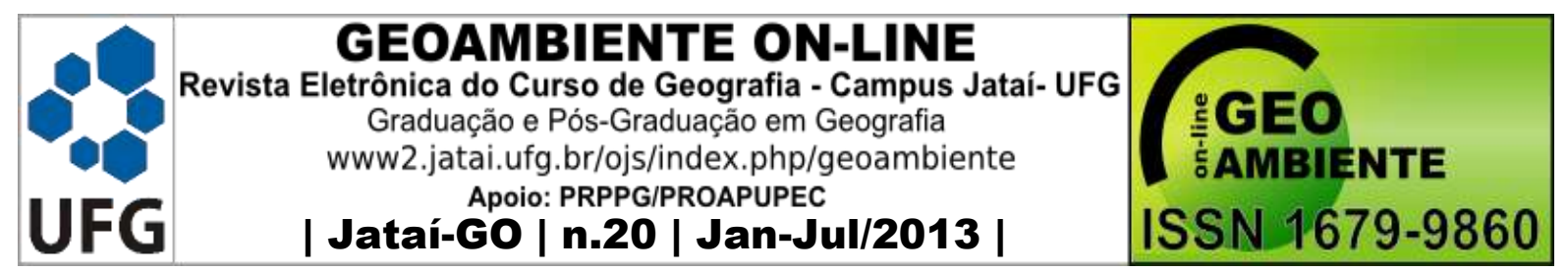

Reserva Legal, passaria a ser apenas de uma fração da área a ser recomposta, se analisada à luz do Código Florestal em vigência.

Mudanças nas porcentagens obrigatórias de áreas de Reserva Legal a serem preservadas, de acordo com a área total e a localização da propriedade, não interfeririam na qualidade técnica da análise, visto que seu procedimento quantitativo permanece inalterado. De modo geral, pode-se afirmar que as maiores dificuldades de aplicação da metodologia aqui apresentada à proposta de reforma do Código Florestal dizem respeito à disponibilidade de imagens com resolução espacial apropriada, para casos como os apresentados no parágrafo anterior, bem como à aplicação da correta interpretação das mudanças propostas ao procedimento prático da análise.

\section{5 - Considerações finais}

A metodologia adotada neste trabalho demonstrou-se eficiente quanto à obtenção de indicadores numéricos que permitam constatar com clareza as condições de cada propriedade nas datas em que foram avaliadas. Como maiores empecilhos mencionam-se as incongruências existentes nos perímetros das propriedades descritos nas próprias matrículas e nos mapas apresentados aos órgãos públicos pelos proprietários, além da falta de definições sobre o tamanho mínimo de um fragmento de mata nativa que possa ser considerado parte integrante da área de Reserva Legal.

Considerando que os resultados obtidos foram satisfatórios para o propósito do trabalho, pode-se afirmar que através do uso de imagens de sensores aerotransportados, sem custos de aquisição, é possível obter bons resultados na análise do uso do solo.

\section{6 - Agradecimentos}

Ao Instituto Brasileiro do Meio Ambiente e dos Recursos Renováveis, Superintendência de Mato Grosso do Sul, por permitir a realização deste estudo, fornecendo o apoio logístico para tal. Em especial: ao chefe da Divisão de Proteção Ambiental (DIPAM) do IBAMA/MS, Jânio Marques, por todo o incentivo e pela confiança; aos Analistas Ambientais: Luiz Augusto Cândido Benatti, Anna Christina Mendo, Reginaldo Gomes Yamaciro, Paula Mochel, Valeriano Souza Neto e Honorato Fernandes por todo o apoio e, acima de tudo, pela extrema paciência, além dos motoristas Diogo e Niltinho. 


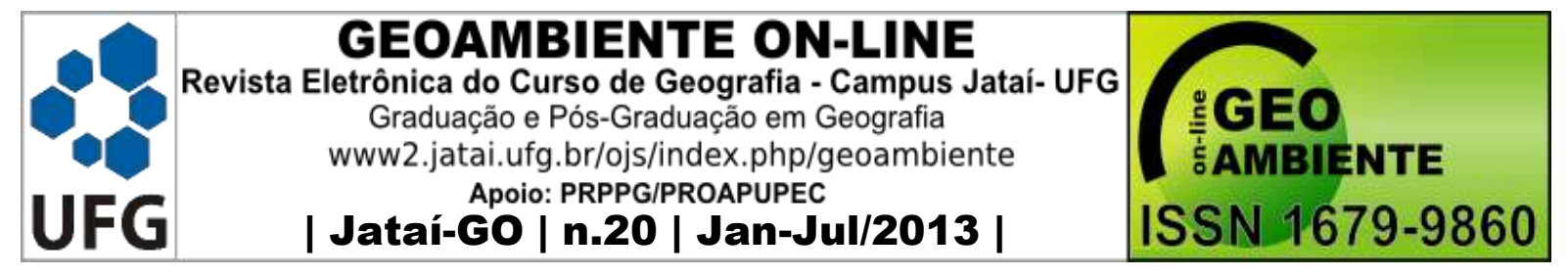

Aos companheiros do Laboratório de Geoprocessamento da UFMS, em especial, à Renata Porto Moraes, por toda a assistência e aos proprietários das fazendas estudadas.

\section{7 - Referências}

ARENA, R. A., BALDASSI, G. A reserva legal no Paraná e os desafios à sua implantação: um estudo sobre os produtores rurais no município de Paranacity-PR. GEOUSP - Espaço e Tempo, São Paulo, № 26, pp. 79 - 91, 2009.

AQUINO, F. de G.; OLIVEIRA, M. C. de. Reserva Legal no Bioma Cerrado: uso e preservação. Planaltina/DF. Embrapa Cerrados. 2006.

AZEVEDO, T. S. de. O uso de geotecnologias na definição das Reservas Legais da bacia do córrego das Posses, Extrema - MG. Anais do XIV Simpósio Brasileiro de Sensoriamento Remoto. Instituto Nacional de Pesquisas Espaciais. Natal, Brasil. p. 3503-3510. 2009.

BASEGGIO J., CARAMORI T. B. A., SORIANI R. R. SIG para mapeamento do uso do solo, com ênfase nas áreas de cobertura vegetal nativa e recursos hídricos, Alto Coxim, MS. In: $1^{\circ}$ SIMPÓSIO DE GEOTECNOLOGIAS NO PANTANAL. p.312-320. 2006.

BRASIL, Leis. Lei n 4.771 de 15 de Setembro de 1965. "Institui o Novo Código Florestal". Data da legislação: 15/09/1.965 - Publicação DOU: 16/09/1965.

BRASIL, Leis. Lei ${ }^{\circ} 8.171$ de 17 de Janeiro de 1991. "Dispõe sobre a Política Agrícola". Data da legislação: 17/01/1.991 - Publicação DOU: 18/01/1991.

BRASIL, Leis. Medida Provisória no 2.166-67 de 24 de Agosto de 2001. "Altera os arts. 1o, 4o, 14, 16 e 44, e acresce dispositivos à Lei no 4.771, de 15 de setembro de 1965, que institui o Código Florestal, bem como altera o art. 10 da Lei no 9.393, de 19 de dezembro de 1996, que dispõe sobre o Imposto sobre a Propriedade Territorial Rural - ITR, e dá outras providências”. Data da legislação: 24/08/2001 - Publicação DOU: 25/08/2001.

BRASIL, Leis. Lei n 12.727 de 17 de Outubro de 2012. "Dispõe sobre a vegetação nativa". Data da legislação: 17/10/2012 - Publicação DOU: 17/10/2012.

CBERS CCD. Imagem de Satélite. Canais 1, 2, 3, 4, 5. 2008a. Disponível em http://www.dgi.inpe.br/. Órbita 163 Ponto 122. Acessado em 15 ago 2008.

CBERS CCD. Imagem de Satélite. Canais 1, 2, 3, 4, 5. 2008b. Disponível em http://www.dgi.inpe.br/. Órbita 163 Ponto 123. Acessado em 15 ago 2008.

CBERS CCD. Imagem de Satélite. Canais 1, 2, 3, 4, 5. 2008c. Disponível em http://www.dgi.inpe.br/. Órbita 162 Ponto 123. Acessado em 02 ago 2008. 


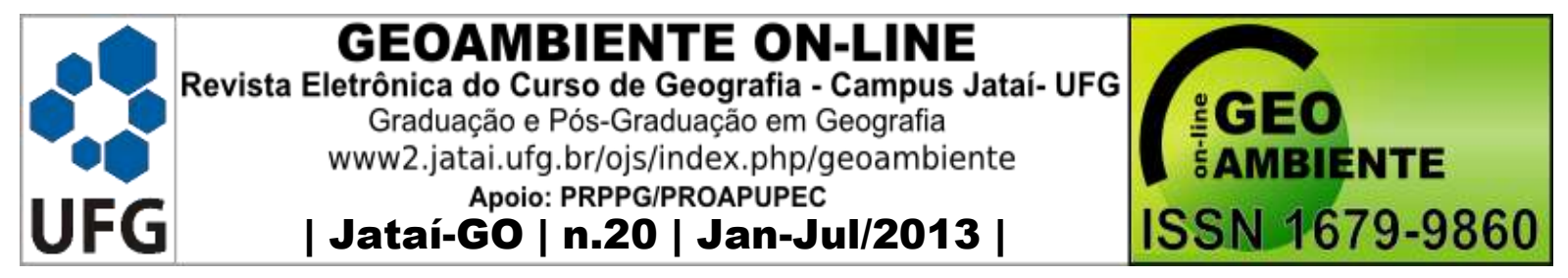

CNA - CONFEDERAÇÃO DA AGRICULTURA E PECUÁRIA DO BRASIL. Afinal, a Lei de Conservação Florestal é Eficaz? Informativo técnico. Revista Gleba. Edição julho/agosto, Brasília. 2001. Disponível em: http://www.cna.org.br/site/noticia.php?n=1186. Acessado em 31 mar 2008.

DGI - DIVISÃO DE GERAÇÃO DE IMAGENS DO INPE - INSTITUTO NACIONAL DE PESQUISAS ESPACIAIS. Catálogo de Imagens. 2008. Disponível em http://www.dgi.inpe.br/CDSR/. Último acesso em agosto de 2008.

ERDAS INC. Erdas Imagine, versão 9.1. Erdas Inc. Atlanta, Geórgia. CD-ROM. 2006.

ESRI INC. 2005. ArcMap, version 9.1. Seattle, Wa, USA. 1 CD-ROM.

FERREIRA JÚNIOR O. INC. GPS TrackMaker PRO, version 4.4. Belo Horizonte, Minas Gerais, Brasil. 1 CD-ROM. 2008.

GARMIN INTERNATIONAL INC. GPS Garmin GPSMAP 60CSx. Olathe, Kansas, USA. 2006.

GLCF - GLOBAL LAND COVER FACILITY. 2008. Disponível em http://www.landcover.org/index.shtml. Acessado em 15 fev 2008.

IBGE - INSTITUTO BRASILEIRO DE GEOGRAFIA E ESTATÍSTICA. Mapas Interativos: Mapa de Vegetação. Atlas Nacional do Brasil - $4^{\text {a }}$ edição. 2002. Disponível em http://mapas.ibge.gov.br. Acessado em 10 set 2008.

IBGE - INSTITUTO BRASILEIRO DE GEOGRAFIA E ESTATÍSTICA. Mapas Interativos: Mapa de Biomas. Mapa de Biomas do Brasil - Primeira Aproximação - escala 1:5.000.000. 2004. Disponível em http://mapas.ibge.gov.br. Acessado em 10 set 2008.

JOELS L. M. Reserva Legal e Gestão Ambiental da Propriedade Rural: Um Estudo Comparativo da Atitude e Comportamento de Agricultores Orgânicos e Convencionais do Distrito Federal. Planeta Orgânico. Distrito Federal. 2002. Disponível em: http://www.planetaorganico.com.br/trabjoels2.htm. Acessado em 31 mar 2008.

LANDSAT TM. Imagem de Satélite. Canais 1, 2, 3, 4, 5, 7. 1984a. Disponível em http://www.dgi.inpe.br/. Órbita 224 Ponto 074. Acessado em 4 mai 2008.

LANDSAT TM. Imagem de Satélite. Canais 1, 2, 3, 4, 5, 7. 1984b. Disponível em http://www.dgi.inpe.br/. Órbita 224 Ponto 075. Acessado em 4 mai 2008.

LANDSAT TM. Imagem de Satélite. Canais 1, 2, 3, 4, 5, 7. 1999. Disponível em http://www.dgi.inpe.br/. Órbita 224 Ponto 074. Acessado em 4 mai 2008. 


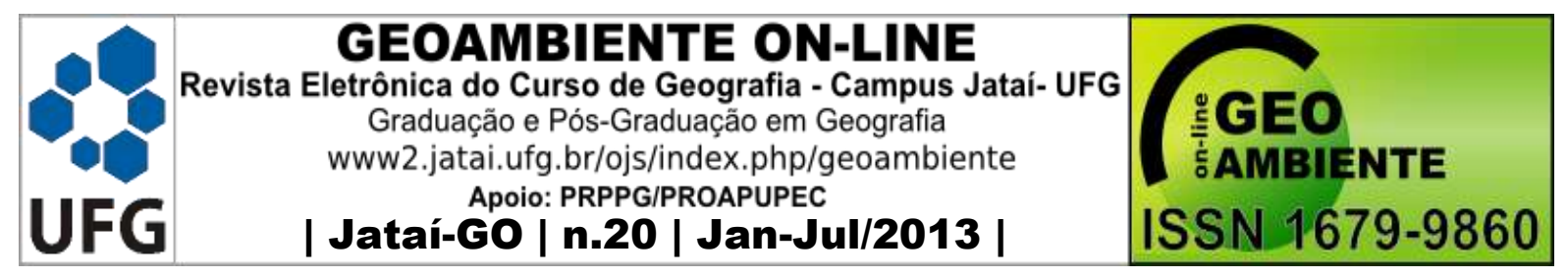

LANDSAT TM. Imagem de Satélite. Canais 1, 2, 3, 4, 5, 7. 2.000. Disponível em http://www.dgi.inpe.br/. Órbita 224 Ponto 074. Acessado em 4 mai 2008.

LANDSAT TM. Imagem de Satélite. Canais 1, 2, 3, 4, 5, 7. 2000. Disponível em http://www.dgi.inpe.br/. Órbita 224 Ponto 075. Acessado em 4 mai 2008.

LILLESAND T. M.; KIEFER R. W.; Chipman, J. W. Remote Sensing and Image Interpretation. John Wiley and Sons. $5^{\text {a }}$ edição. 2000.

MACARTHUR R.H.; WILSON E.O. The theory of island biogeography. Princeton University Press, Princeton. 1967, 203 pp.

MARTINS, C. de A.; OLIVEIRA, A. K. M. de.; BERNARDES, C. R. Geoprocessamento como instrumento para a avaliação do cumprimento do código florestal em área de extração de carvão vegetal no Pantanal do Negro, Mato Grosso do Sul. In: SIMPÓSIO DE GEOTECNOLOGIAS NO PANTANAL, 2., 7-11 nov. 2009, Corumbá. Embrapa Informática Agropecuária/INPE. Anais... Mato Grosso do Sul: INPE. p. 470-479. 2009.

MATO GROSSO DO SUL, Leis. Decreto n 11.700 de 8 de Outubro de 2004. "Institui o Sistema de Recomposição, Regeneração e Compensação da Reserva Legal no Estado do Mato Grosso do Sul”. Data da legislação: 08/10/2.004 - Publicação DOU: 13/10/2004.

MATO GROSSO DO SUL, Leis. Decreto n ${ }^{\circ} 12.528$ de 27 de Março de 2.008. "Institui o Sistema de Reserva Legal (SISREL) no Estado do Mato Grosso do Sul, e dá outras providências". Data da legislação: 27/03/2.008 - Publicação no Diário Oficial de Mato Grosso do sul: 29/03/2008.

NASA - NATIONAL AERONAUTICS AND SPACE ADMINISTRATION. Earth Science Applications Directorate-MrSid Image Server. Disponível em https://zulu.ssc.nasa.gov/mrsid. 2005 .

PARANHOS FILHO A.C. Análise Geo-Ambiental Multitemporal: O estudo de Caso da Região de Coxim e Bacia do Taquarizinho. Tese de Doutorado. UFPR, Curso de PósGraduação em Geologia, Curitiba, 213 p. 2000.

PCI GEOMATICS. Geomatica version 9.1 for Windows. Ontário, Canadá. 1 CD-ROM. 2003 RIGONATTO C. A.; NOGUEIRA J. M. Política Ambiental: Uma Avaliação da Eficácia da Reserva Legal. 2006. In: VII Congresso Alasru (Asociación Latinoamericana de Sociología Rural). Quito, Anais. Disponível em: http://www.alasru.org/cdalasru2006/14\%20GT\%20 Claudinei\%20Antonio\%20Rigonatto.pdf. Acessado em 31 mar 2008. 


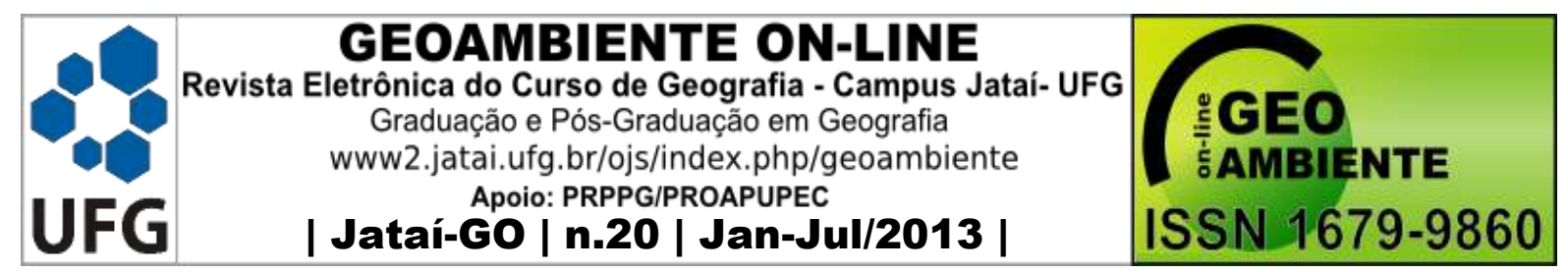

SILVA APARECIDA, A. Monitoramento Ambiental em Áreas de Cerrado a partir de dados de Sensoriamento Remoto. Relatório Final de Pesquisa apresentado à Coordenação de Pesquisa, Pró-Reitoria de Pesquisa e Pós-Graduação, Universidade Estadual de Goiás. 2005. STEFANES M.; PARANHOS FILHO A. C.; TERUYA JÚNIOR H., FERREIRA L. M.; SILVEIRA E. M.S. Avaliação do Uso do Mosaico Geocover, como Base para Georreferenciamento de Imagens CBERS 2 - sensor CCD. In: IV SBEA. 2005.

TANCREDI, N. S. H., ALMEIDA, J. R. de, LINS, G. A., GUERRA, A. J. T., JORGE, M. do C. O. Uso de geotecnologias em laudos periciais ambientais: estudo de caso no município de jacundá, Pará. Revista Geografar. Curitiba, v.7, n.1, p.1-19, 2012.

XAVIER, R. C. Capacitação de agentes ambientais do IBAMA: O uso das ferramentas de Geoprocessamento no combate a crimes ambientais. In: SIMPÓSIO BRASILEIRO DE SENSORIAMENTO REMOTO, 13., 21-26 abr. 2007, Florianópolis. Brasil. INPE. Anais... Florianópolis: INPE, p. 157-1589. 2007. 